\title{
REVIEW ARTICLE OPEN From purines to purinergic signalling: molecular functions and human diseases
}

\author{
Zhao Huang ${ }^{1}$, Na Xie ${ }^{1}$, Peter Illes ${ }^{2,3}$, Francesco Di Virgilio ${ }^{4}$, Henning Ulrich ${ }^{2,5}$, Alexey Semyanov $\mathbb{E}^{6,7}$, Alexei Verkhratsky $\mathbb{B}^{2,7,8}$, \\ Beata Sperlagh ${ }^{9}$, Shu-Guang $\mathrm{Yu}^{2,10}$, Canhua Huang $\mathbb{D}^{1,11}$ and Yong Tang $\mathbb{B}^{2,10}$
}

Purines and their derivatives, most notably adenosine and ATP, are the key molecules controlling intracellular energy homoeostasis and nucleotide synthesis. Besides, these purines support, as chemical messengers, purinergic transmission throughout tissues and species. Purines act as endogenous ligands that bind to and activate plasmalemmal purinoceptors, which mediate extracellular communication referred to as "purinergic signalling". Purinergic signalling is cross-linked with other transmitter networks to coordinate numerous aspects of cell behaviour such as proliferation, differentiation, migration, apoptosis and other physiological processes critical for the proper function of organisms. Pathological deregulation of purinergic signalling contributes to various diseases including neurodegeneration, rheumatic immune diseases, inflammation, and cancer. Particularly, gout is one of the most prevalent purine-related disease caused by purine metabolism disorder and consequent hyperuricemia. Compelling evidence indicates that purinoceptors are potential therapeutic targets, with specific purinergic agonists and antagonists demonstrating prominent therapeutic potential. Furthermore, dietary and herbal interventions help to restore and balance purine metabolism, thus addressing the importance of a healthy lifestyle in the prevention and relief of human disorders. Profound understanding of molecular mechanisms of purinergic signalling provides new and exciting insights into the treatment of human diseases.

Signal Transduction and Targeted Therapy (2021)6:162 ； https://doi.org/10.1038/s41392-021-00553-z

\section{INTRODUCTION}

Purines and pyrimidines have long been recognised as fundamental elements of bioenergetics; while their role as chemical transmitter was suggested 90 years ago, when in 1929, Albert Szent-Gyorgyi and Alan Drury discovered that intravenous injection of adenine into guinea pig disturbed cardiac rhythm, indicating extracellular signalling function. ${ }^{1}$ Nearly two decades later, Wilhelm Feldberg and Catherine Hebb reported that adenosine triphosphate (ATP) stimulated the sympathetic ganglion in the cat. $^{2}$ In 1959 Pamela Holton demonstrated that antidromic stimulation of sensory nerves in the rabbit led to the release of ATP. ${ }^{3}$ These findings suggested transmitter function of purines in the nervous system. In 1972, Geoffrey Burnstock proposed the purinergic neurotransmission hypothesis, which described ATP as the non-adrenergic and non-cholinergic neurotransmitter. ${ }^{4}$ This hypothesis failed to convince most researchers at first, but has been gradually accepted after molecular cloning of purinergic receptors which mediate signal transduction in response to extracellular purines has been accomplished. Purinergic receptors are commonly divided into two classes based on agonist selectivity, namely P1 adenosine receptors, and P2 nucleotide receptors (also known as ATP receptors). ${ }^{5}$ These receptors are further sub-classified into several subtypes, which are diffusely expressed in tissues and are activated by different purine derivatives, thereby exerting specific physiological functions.

Purinergic signalling interacts with other signal molecules to form a complex network, regulating numerous cellular processes including proliferation, differentiation, and death. For instance, ATP activates metabotropic $\mathrm{P} 2 \mathrm{Y}$ receptor to promote cell proliferation, while activation of ionotropic $\mathrm{P}_{2} \mathrm{X}_{7}$ receptor arrests growth through recruiting protein kinases $\mathrm{p} 38 / \mathrm{MAPK}$ and SAPK/JNK. ${ }^{6}$ Given the key role of purines in fundamental metabolic processes, and the involvement of purinergic transmission in the regulation of fundamental physiological processes (such as blood coagulation ${ }^{7}$ and neurotransmission ${ }^{8}$ ), deregulation and malfunction of the purine/purinergic system contributes to pathophysiology of numerous diseases, including gout, diabetes, neurological disease, osteoporosis and cancer (Fig. 1).

The best-known purine-related disease is gout, which results from accumulation of urate crystals in joints. Deposition of urate crystals is frequently associated with a purine-rich diet

\footnotetext{
${ }^{1}$ State Key Laboratory of Biotherapy and Cancer Center, West China Hospital, and West China School of Basic Medical Sciences \& Forensic Medicine, Sichuan University, and Collaborative Innovation Center for Biotherapy, Chengdu, China; ${ }^{2}$ International Collaborative Centre on Big Science Plan for Purinergic Signalling, Chengdu University of Traditional Chinese Medicine, Chengdu, China; ${ }^{3}$ Rudolf-Boehm-Institut für Pharmakologie und Toxikologie, Universitaet Leipzig, Leipzig, Germany; ${ }^{4}$ Department of Medical Sciences, University of Ferrara, Ferrara, Italy; ${ }^{5}$ Department of Biochemistry, Institute of Chemistry, University of São Paulo, São Paulo, Brazil; ${ }^{6}$ Shemyakin-Ovchinnikov Institute of Bioorganic Chemistry, Russian Academy of Sciences, Moscow, Russia; ${ }^{7}$ Sechenov First Moscow State Medical University, Moscow, Russia; ${ }^{8}$ Faculty of Biology, Medicine and Health, The University of Manchester, Manchester, UK; ${ }^{9}$ Department of Pharmacology, Institute of Experimental Medicine, Hungarian Academy of Sciences, Budapest, Hungary; ${ }^{10}$ Acupuncture and Chronobiology Key Laboratory of Sichuan Province, Chengdu, China and ${ }^{11}$ School of Basic Medical Sciences, Chengdu University of Traditional Chinese Medicine, Chengdu, China

Correspondence: Canhua Huang (hcanhua@scu.edu.cn) or Yong Tang (tangyong@cdutcm.edu.cn)
}

These authors contributed equally: Zhao Huang, Na Xie

Received: 12 November 2020 Revised: 24 January 2021 Accepted: 24 February 2021

Published online: 28 April 2021 


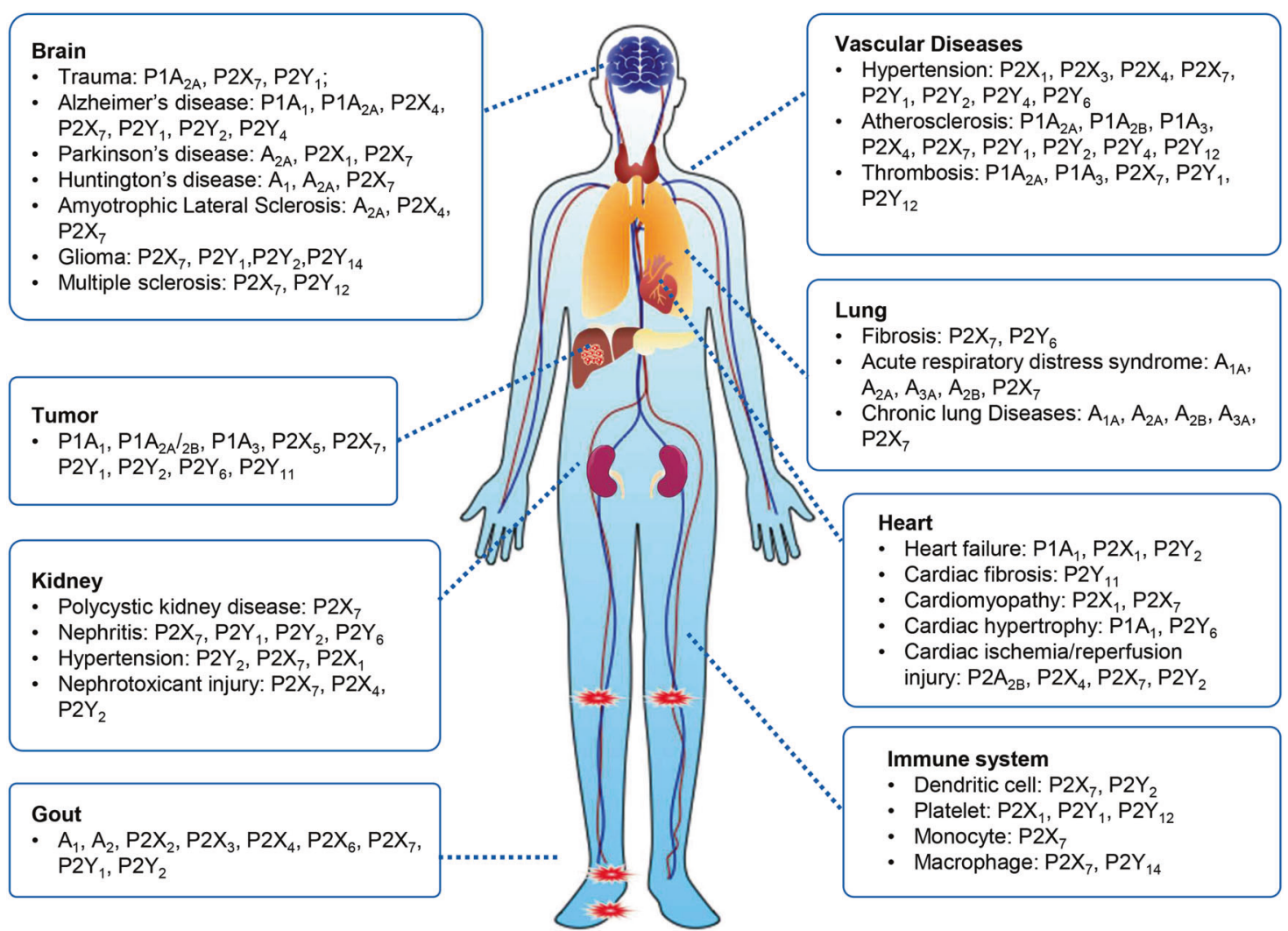

Fig. 1 The causative role of purinergic signalling in human diseases. Purinoceptors, including P1, P2X and P2Y receptors, are diffusely expressed in every human body part, such as the nervous system, circulatory system, respiratory system, immune system, urinary system and others. Dysregulation of purinoceptors function leads to various diseases, including neurological, rheumatic, cardiovascular, cancer diseases and so on

(i.e. seafood, animal offal, beer, etc.) or with renal insufficiency. To date, several drugs targeting purine metabolism or purinergic receptors have been developed (including tecadenoson, regrelor, AF-219, JNJ-54175446, PPADS, A317491, etc.), and many such drugs underwent successful trials or have been approved by the US Food and Drug Administration (FDA) (for example regadenoson, istradefylline, dipyridamole, clopidogrel, prasugrel, cangrelor, ticagrelor, etc.), further highlighting the importance of targeting purinergic signalling in the clinic. In this review, we shall briefly summarise main concepts and recent findings in purine biogenesis and metabolism, with a focus on the role of purinergic signalling in cellular functions and several human diseases including neurological disorders, rheumatic diseases and cancer. We shall also discuss therapeutic approaches, with a focus on traditional Chinese medicine (TCM) as a novel option for restoring the balance of purine metabolism.

\section{PURINOSOME AS THE FUNDAMENTAL UNIT TO REGULATE PURINE METABOLISM}

Purine metabolism affects a broad range of cellular processes, including energy production and DNA/RNA synthesis. ATP is hydrolysed to ADP and further to AMP, thereby meeting energy demand and facilitating nucleotide assembly. Cyclic AMP (CAMP) is the omnipresent second messenger controlling cellular physiological responses, further highlighting the crucial role of purine metabolism for the proper function of organisms. AMP can be dephosphorylated into adenosine, which is shuttled across cell membrane via equilibrative and concentrative nucleoside transporters (respectively, ENT and CNT) ${ }^{9}$. Adenosine translocation by ENT equalises adenosine levels on both sides of cell membrane, while CNT transports adenosine against a concentration gradient into the cells to maintain a high adenosine level inside the cell. ${ }^{9}$ Adenosine can be either recycled as AMP by phosphorylation, or converted into uric acid as the final metabolite. On the other hand, AMP and other purine nucleotides (i.e. inosine monophosphate (IMP), xanthosine monophosphate (XMP), and guanosine monophosphate (GMP)) can be converted into each other therefore generating a cellular purine pool. There are two major pathways maintaining this pool, namely the salvage cascade and de novo synthesis (Fig. 2). ${ }^{10}$ The salvage pathway provides purine nucleotide source by recycling degraded bases. In this cascade, AMP can be generated from adenine, this reaction being catalysed by the adenine phosphoribosyltransferase (APRT). ${ }^{11}$ Other purine nucleotides such as IMP and GMP can be produced from hypoxanthine and guanine, respectively; these processes are catalysed by hypoxanthine-guanine phosphoribosyltransferase (HPRT). ${ }^{12}$ Cells prefer salvage pathway over the de novo synthesis because of lower energy costs. Besides, many cellular populations (for example brain or bone marrow cells) lack the de novo purine synthesis cascade, being thus highly dependent on the salvage pathway. ${ }^{13,14}$

When purines are in deficit, the energy intensive de novo pathway is upregulated to meet increasing purine demand. Briefly, de novo purine synthesis pathway begins with the consumption of phosphoribosyl pyrophosphate (PRPP), and terminates with the production of IMP. The entire de novo pathway is comprised of 10 highly regulated reactions but only six enzymes are identified as direct participants, because some of enzymes are multi-functional thus capable of catalysing more than one reaction. ${ }^{15}$ For instance, trifunctional purine biosynthetic protein adenosine-3 (trifGART) catalyses three steps, namely conversion of 5-phosphoribosylamine (PRA) to glycinamide ribonucleotide (GAR), of GAR to $\mathrm{N}$-formylglycinamide ribonucleotide (FGAR), and $\mathrm{N}$-formylglycinamidine ribonucleotide (FGAM) to aminoimidazole ribonucleotide (AIR) by its GAR synthetase (GARS), 


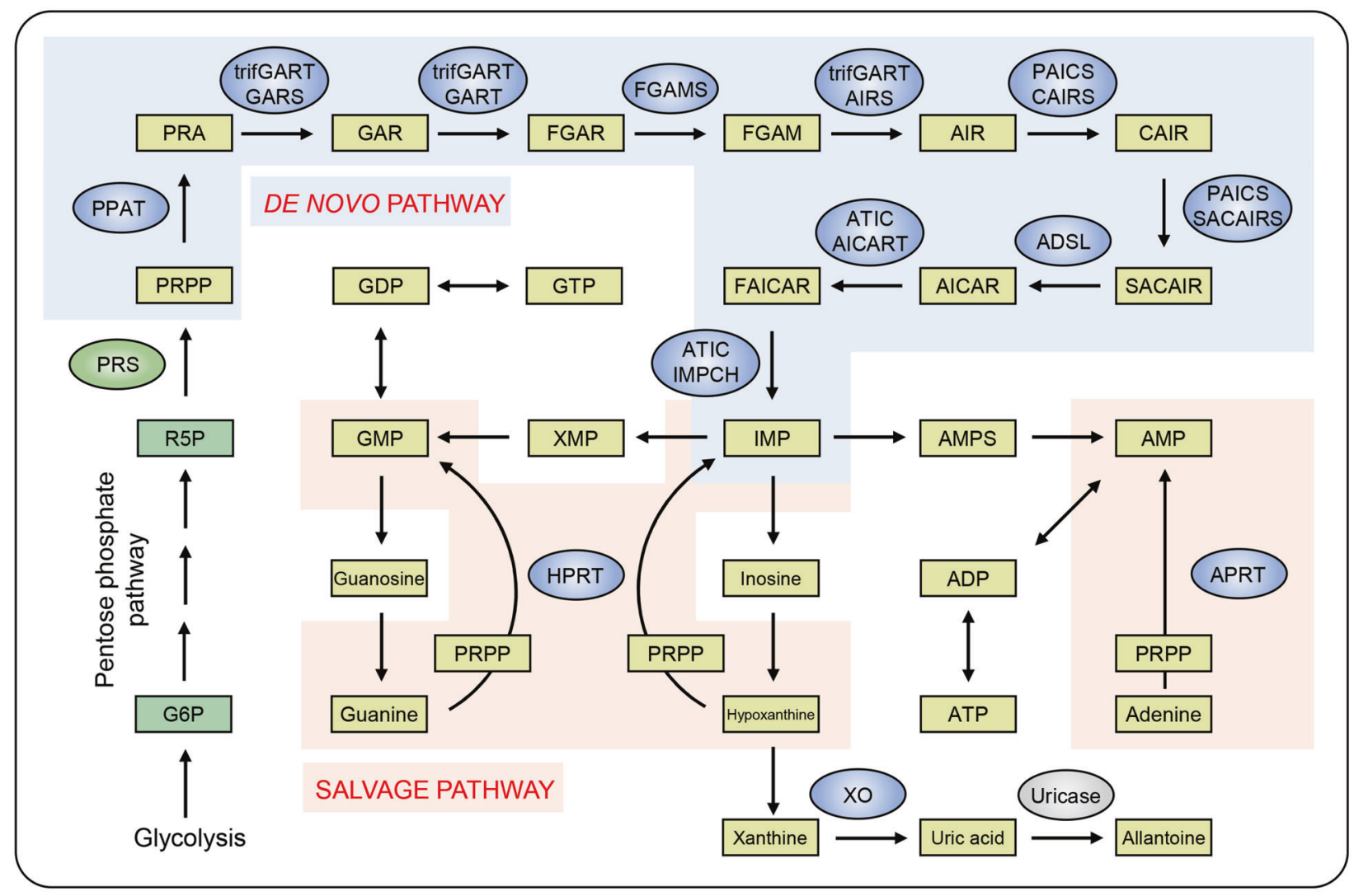

Fig. 2 De novo and salvage pathway for purine synthesis. PRPP generated from glycolysis and pentose phosphate pathway (green) serves as substrate for de novo purine synthesis (blue background). After 10-step reaction catalysed by six enzymes with different functional domains, IMP is produced as the end of de novo pathway. Salvage pathway (orange background) is mainly catalysed by two enzymes, namely HPRT and APRT. In this pathway, PRPP is also needed, and several nucleosides serve as co-substrates for the production of nucleotides. The final metabolite uric acid is further oxidised by uricase (grey), which is expressed in most organisms but lost in humans and a part of primates

GAR transformylase (GART), and AIR synthase (AIRS) domain, respectively. ${ }^{16}$ Two other enzymes, the multifunctional protein ADE2 (PAICS) and bifunctional purine biosynthesis protein PURH (ATIC), catalyse two steps. ${ }^{17,18}$ Remaining three enzymes, namely PRPP amidotransferase (PPAT), FGAM synthetase (FGAMS), and adenylosuccinate lyase (ADSL) are identified as monofunctional enzymes that catalyse only one reaction during the de novo purine synthesis. ${ }^{19-21}$ In addition to higher energy cost, the de novo pathway consumes more amino acids (i.e. glutamine, glycine, aspartate) and additional metabolites (i.e. formate and carbon dioxide) compared with the salvage pathway. This metabolic shift resembles several hallmarks of cancer: rapidly proliferating cancer cells require more amino acids (particularly glutamine) and favour acidic tumour microenvironment, suggesting a potential link between upregulated de novo purine synthesis and carcinogenesis. This matter will be discussed in following section.

To improve the utilisation of substrates and accelerate metabolic flux, metabolic enzymes tend to form complexes known as metabolon, frequently found in numerous metabolic pathways, including glycolysis and tricarboxylic acid cycle (TCA cycle). For example, the metabolon of glycolysis, termed a glycosome, is a multi-enzyme structure containing a series of glycosomal enzymes including hexokinase (HK), phosphofructokinase (PFK), alanine transferase (ALT) and many others. ${ }^{22}$ Similar metabolon also exists in the de novo purine synthesis pathway. Using fluorescence imaging technique, all six enzymes in the de novo pathway have been found to interact with each other to form a metabolon, defined as "purinosome". ${ }^{23}$ In response to limited purine supplement, the purinosome promotes production of purines to meet nutrient demand. In HPRT1-mutated cells, that lack purine salvage capability, purinosome assembly undergo a $25 \%$ increase. ${ }^{24}$ In purinosome-rich cells, a 3 -fold increase in IMP level was observed compared with normal cells. ${ }^{25}$ Binding efficiencies among six enzymes within purinosome are not comparable. The three enzymes PPAT, trifGART and FGAMS bind each other with a strong interaction thus forming the core of purinosome. In contrast the interaction of PAICS, ADSL and ATIC is relatively weak making them peripheral components. ${ }^{26}$ In addition to six de novo synthesis enzymes, some other purine-related enzymes are included in the purinosome, indicating that the purinosome is not only involved in the de novo purine synthesis, but contributes to other purine metabolic pathways. One of these additional components is adenylsuccinate synthase (ADSS), which catalyses the biogenesis of AMP from IMP. ${ }^{25}$ The inosine monophosphate dehydrogenase (IMPDH) that catalyses conversion of IMP to XMP, is also a member of purinosome. ${ }^{25}$ Several non-enzyme proteins that seem to be irrelevant for purine metabolism are also included in purinosome, such as the chaperones HSP70 and HSP90. ${ }^{27}$ The formation of purinosome is highly dynamic, for the depletion of purines in the medium promotes the assembly of purinosome, while a purine-rich medium leads to disassociation of the enzyme complex. ${ }^{23}$ These observations suggest that under purine-rich or depleted conditions, cells are capable to perceive extracellular purine level and regulate de novo purine synthesis by dynamically controlling the assembly and turnover of purinosome.

Although the dynamic regulation of purinosome formation and disassembly has been described long time ago, the underlying molecular cascades remain largely undefined. The finding that key 


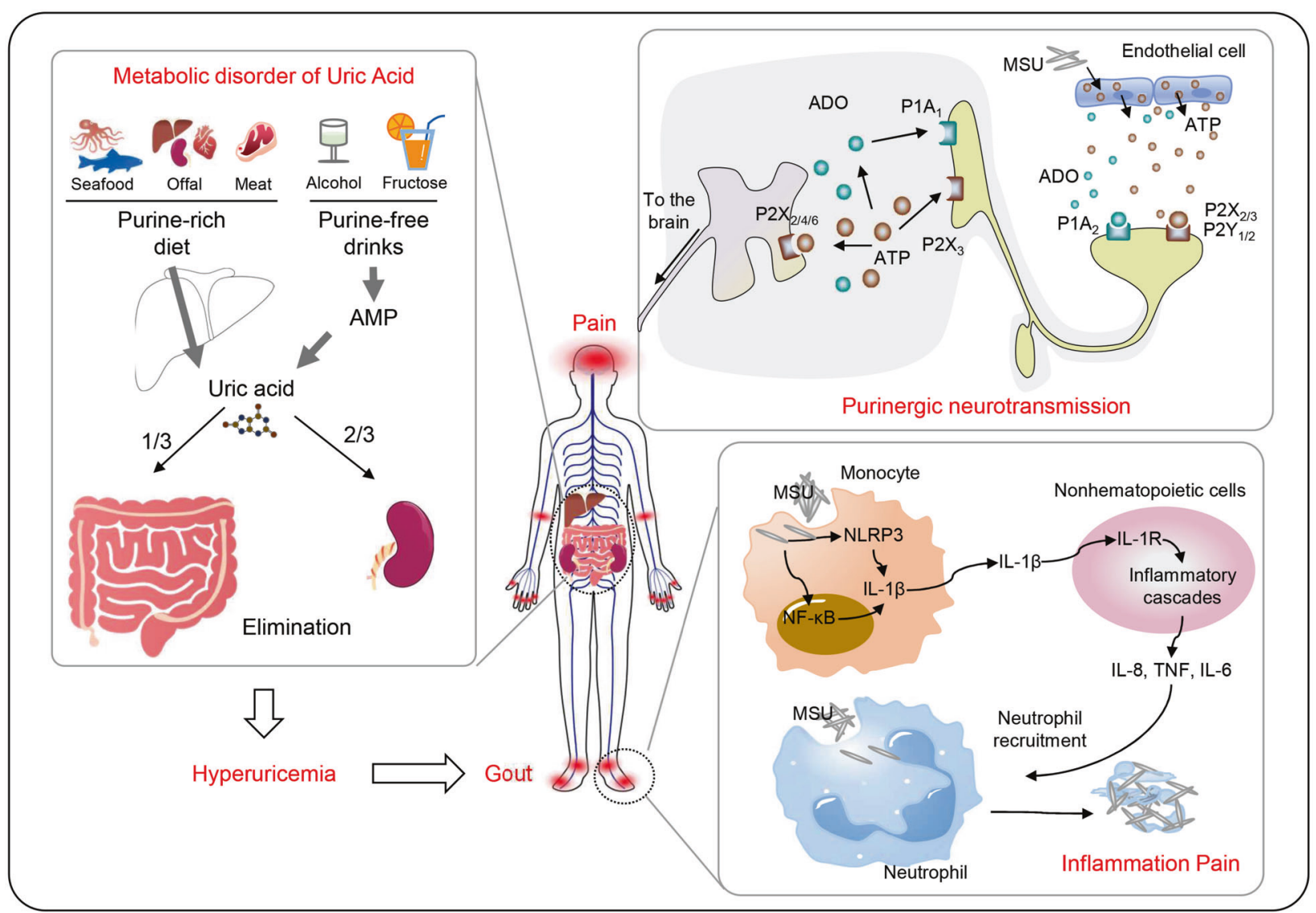

Fig. 3 Dysregulated purine metabolism contributes to gout and pain. Purine-rich diet and several beverages, including meat, seafood, animal offal, beer and fructose containing drinks, lead to high level of uric acid in vessel, termed hyperuricemia. Deposition of urate in joint induces local inflammation. In this process, adenosine (ADO) and ATP function as neurotransmitters to activate P1 and P2 purinergic receptors, respectively. This purinergic neurotransmission induces intense pain in gout patients

components of purinosome undergo phosphorylation implies that certain kinase signalling pathways are critical to this process. A highthroughput study targeting human kinome revealed that the mammalian target of rapamycin (mTOR) facilitates the colocalisation of purinosome with mitochondria, which are required for optimal function of the purinosome itself. ${ }^{28}$ Given the high energy demand of the de novo purine synthesis, the spatial colocalisation with mitochondria provides high concentrations of ATP to support a series of purinosome-associated enzymatic reactions. Purines thus generated can be immediately utilised for the production of ATP. It is not surprising that microtubule participates in this spatial organisation of purinosome, for cytoskeleton largely affects the formation and disassociation of protein complexes and regulates their subcellular localisation. This hypothesis is supported by the finding that the purinosome is co-localised with microtubule, and disruption of the microtubule network impedes de novo purine synthesis. ${ }^{29}$ Microtubule depolymerisation by nocodazole treatment abrogates the co-localisation between purinosome and mitochondria, indicating that microtubule-directed transport contributes to purinosome-mitochondria co-localisation. ${ }^{30}$ The mTOR indeed regulates microtubule-dependent protein transport. ${ }^{31}$ This evidence suggests that mTOR-microtubule-purinosome-mitochondria axis plays a central role in the complex formation and spatial regulation of purinosome. Apart from mTOR, other kinases may also be involved in this process. For instance, inhibition of casein kinase II (CK2) has been shown to induce a disassociation of purinosome clusters and affect de novo purine biosynthesis in HeLa cells. ${ }^{32}$ Moreover, 3-phosphoinositide-dependent protein kinase 1 (PDK1) has been found to regulate the core assembly of purinosome through its cytoplasmic activity, but independent of its membrane-bound activity. ${ }^{33}$ It is worth mentioning that G-protein coupled receptor (GPCR) signalling, which regulates a great number of kinases such as PI3K, PKA, Akt, PKC, facilitates purinosome assembly, suggesting that additional kinases are probably involved. ${ }^{34}$

\section{ABERRANT PURINE METABOLISM CAUSES HYPERURICEMIA AND GOUT}

Gout, the archetypal purine-related disease has an estimated incidence between $2.7 \%$ and $6.7 \%$ that is positively correlated with a western lifestyle. ${ }^{35}$ In mainland China, the incidence of gout was $0.9 \%$ in 2000-2005 but increased to $1.4 \%$ in 2011-2014, which reflects a rapid metamorphosis in the life style. ${ }^{36}$ Hyperuricemia is the major risk factor for gout, as it is caused by deposition of the monosodium form of urate (MSU) in the joints. ${ }^{37}$ Urate is the final metabolite of purine metabolism, and therefore dysregulation of purine catabolism contributes to gout (Fig. 3). There are multiple causes accounting for hyperuricemia and the deposition of MSU. Firstly, a purine-rich diet induces urate overproduction. Purine-rich foods include seafood, meat, animal offal, and alcoholic beverages, which all are associated with prosperous living condition. Alcohol and certain purine-free drinks, including fructose-containing beverage are also risk factors due to their ability to accelerate nucleotide breakdown, therefore increasing urate production. ${ }^{38-40}$ Conversion of fructose into fructose-1-phosphate requires consumption of ATP, leading to increased AMP level. Accumulated AMP enters into purine catabolic pathway to produce uric acid. ${ }^{41}$ Similarly, alcohol metabolism in liver consumes a large amount of ATP to generate AMP and thereby contributes to hyperuricemia. ${ }^{42}$ Secondly, loss of uricase (also known as urate oxidase) also probably leads to MSU 
deposition. In most organisms from bacteria to mammals, urate is oxidised by uricase to form soluble allantoin to avoid deposition. However, in humans and parting in some primates, this enzyme is lost. ${ }^{43}$ Given that urate also functions as an antioxidant, loss of uricase provides substantial advantages for humans against oxidative stress-related diseases such as neurodegeneration and cancer. ${ }^{44}$ From this perspective, potential side effects should be considered while treating gout with recombinant uricase. ${ }^{45}$ Thirdly, compromised excretion by kidneys and gut largely contributes to hyperuricemia. Approximately two-thirds of uric acid is excreted by kidneys, while gastrointestinal tract is responsible for the remaining one-third. ${ }^{46}$ This explains why the elders, in whom renal and gastrointestinal function is impaired, are more likely to have gout.

Mechanistic studies revealed that transporter-mediated urate traffic is closely associated with hyperuricemia induced by renal and gastrointestinal underexcretion. Serum urate level is mainly determined by four transporters, namely URAT1 (encoded by gene SLC22A12), GLUT9 (SLC2A9), NPT1 (SLC17A1) and ABCG2. ${ }^{47}$ In kidney, proximal tubular cells express all four transporters to balance serum urate. URAT1 localises at the apical side of proximal tubular cells, importing urate from renal tubule into lining cells. ${ }^{48}$ A fraction of cellular urate is then transported to blood via GLUT9, which localises at the basolateral side of proximal tubular cells. ${ }^{49}$ Alternatively, cellular urate can also be excreted into renal tubule via ABCG2 and NPT1, both of which localise at the apical side of proximal tubular cells. ${ }^{50,51}$ ABCG2 has been also found on the apical side of enterocyte, excreting urate into intestinal lumen. ${ }^{52}$ Clinical data suggest that a number of single-nucleotide polymorphisms (SNPs) exist in the encoding genes, leading to gain-of-function or loss-of-function in these four transporters. Thus, gain-of-function SNP in URAT1 and GLUT9, as well as loss-offunction SNP in ABCG2 and NPT1 increase the risk of gout. In contrast, loss-of-function mutations of the former two genes or gain-of-function mutation in the latter two may reduce the risk of gout. For instance, $\mathrm{R} 90 \mathrm{H}$ and $\mathrm{W} 258 \mathrm{X}$ non-functional mutations of URAT1 have been shown to decrease the risk of hyperuricemia. ${ }^{53}$ In addition, loss-of-function mutations of GLUT9 (i.e. C210F, N333S, etc.) are associated with lower serum urate. ${ }^{54}$ Introduction of the Q141K mutation (linked to a common SNP rs2231142) to $A B C G 2$ halved urate transport hence reducing its contribution to development of gout. ${ }^{55}$ The gain-of-function mutation, I269T on NPT1, facilitates urate clearance and decreases the risk of gout. ${ }^{51}$ Moreover, these critical transporters might be regulated by genetic variants present in other genes. A recent genome-wide association study (GWAS) identified 183 loci associated with serum urate levels. Among these SNPs, the T139l on HNF4A upregulates its ability to activate $A B C G 2$ promoter, leading to ABCG2 overexpression, which is negatively associated with serum urate level. ${ }^{56}$ Such genetic modifications are much more complicated, thus again highlighting the importance of a balanced diet in the prevention and relieve of hyperuricemia.

The definition of hyperuricemia is based on the laboratory data showing that urate begins to crystallise at a concentration of $0.41 \mathrm{mmol} / \mathrm{L}$. ${ }^{57}$ Those crystals, known as MSU depositions, can be detected by microscopy and used as the gold standard for the diagnosis of gout. The preferred sites of MSU deposition are joints, including first metatarsophalangeal joint, ankle, knee, and organs such as the kidney. Deposition of MSU leads to acute inflammation and intense pain known as gout flare. Inflammation at affected joints is largely induced by the recruitment of immune cells (i.e. infiltrating macrophages, neutrophils, etc.) and accumulation of proinflammatory cytokines (i.e. IL-1 $\beta$, IL-6, etc.). ${ }^{58}$ Mechanistic studies demonstrated that MSU crystals bind to membranes of macrophages instigating potassium efflux and the activation of NLRP3 inflammasome. ${ }^{59}$ This allows autocleavage of pro-caspase- 1 into its mature form, which in turn processes pro-IL-1 $\beta$ to bioactive IL-1 $\beta$. After activation of macrophages, neutrophils are recruited to inflammatory sites where they generate reactive oxygen species (ROS) and pro-inflammatory cytokines, thereby enhancing gout flare. ${ }^{60}$ Gout flare is a self-limiting process that resolves within about 10 days, probably because of build-up of anti-inflammatory cytokines including IL-10, TGF $\beta 1$ and IL-37. ${ }^{61,62}$ Neutrophils also play a role in the resolution of gout flare. Mounting a defensive response, neutrophils release their contents including chromosomal DNA and proteins to form neutrophil extracellular traps (NETs), which sequester pro-inflammatory cytokines such as IL-6 and TNF.63 Despite a transient relief of gout flare, MSU crystals fail to be removed from affected joint sites. Instead, MSU crystals bind to NETs, and aggregate in the connective tissue to form subcutaneous nodules termed tophi, the presence of which indicates a late stage of gout known as tophaceous gout. ${ }^{64}$ It may take decades to develop tophaceous gout after the first attack of gout flare, and a uratelowering therapy is effective for arresting this severe disease. ${ }^{65}$ Tophaceous gout is frequently accompanied by bone damage. It has been shown that MSU crystals deposit on the synovial surface, causing a cortical break then progresses into bone erosion. ${ }^{66}$ Mechanistic studies demonstrated that MSU crystals reduce the viability of osteoblasts but enhance the development of osteoclast, leading to a resorptive state and subsequent bone loss. ${ }^{67,68}$ In line with it, a large-scale epidemiologic study revealed a $20 \%$ increased risk of osteoporosis in patients with gout compared with gout-free controls. ${ }^{69}$

Numerous studies indicate that lifelong urate-lowering therapy is the key for the management of gout. Based on metabolic pathways of urate production and turnover, several pharmacological strategies have been developed to achieve these blood urate targets. Uric acid is generated through the oxidation of xanthine by xanthine oxidase, therefore two inhibitors of xanthine oxidase, allopurinol and febuxostat, are currently used as the first-line defence agents. $^{70}$ Allopurinol is a hypoxanthine analogue that binds and inhibits xanthine oxidase. ${ }^{71}$ In addition to decreasing uric acid production, inhibition of xanthine oxidase also results in an accumulation of hypoxanthine, which enters purine salvage pathway. This effect probably induces feedback inhibition of PPAT, the first enzyme of purine de novo synthesis to further block urate production. ${ }^{22}$ In clinical practices, dose escalation of allopurinol showed a better urate-lowering effect without increasing adverse responses. ${ }^{73}$ The safety of this drug is closely related to individual genetic and renal function. A rare but severe side effect, allopurinol hypersensitivity syndrome, may occur in patients carrying the HLA-B ${ }^{*} 5801$ allele. ${ }^{74}$ Allopurinol usage can likely be a risk factor for renal disease. ${ }^{75}$ Allopurinol taken orally, rapidly metabolises into oxipurinol, which is slowly excreted by kidney. ${ }^{76}$ Given that gout patients frequently suffer from kidney impairment, administration of allopurinol probably increases the renal burden. This finding however, is controversial. A large-scale study indicated that allopurinol decreases the risk of chronic kidney diseases, suggesting the impact of allopurinol on kidney needs to be further examined. ${ }^{77}$ In contrast, another drug febuxostat is metabolised by liver and therefore it is not likely to impair kidney function. In hyperuricemic patients with chronic kidney diseases, febuxostat has been shown to be a better choice than allopurinol for delaying renal impairment. ${ }^{78}$ Febuxostat however, may cause acute liver injury. ${ }^{79}$ Moreover, treatment with febuxostat led to a higher mortality in gout patients with cardiovascular diseases, compared with allopurinol. ${ }^{80}$ Taken together, these observations suggest that both xanthine oxidase inhibitors hold curative effectiveness although potential side effects should not be overlooked. In addition to severity, therapeutic options depend on a variety of factors including individual genetic variation and the condition of kidney, liver as well as cardiovascular system. ${ }^{35,81}$

\section{PURINOCEPTORS IN PATHOPHYSIOLOGY}

Purines exert essential pathophysiological effects by acting at purinergic receptors, the concept of which was introduced by 
Geoffrey Burnstock. ${ }^{82}$ Purinergic receptors are divided into two subfamilies known as $\mathrm{P} 1$ and $\mathrm{P} 2$ receptors. P1 receptors are Gprotein-coupled receptors that recognise adenosine as endogenous ligand and are involved in a large number of physiological responses, such as modulation of heart rhythm. ${ }^{83}$ In early 1990s, four members of $P 1$ receptor family $A_{1}, A_{2 A}, A_{2 B}$ and $A_{3}$, were cloned and characterised. ${ }^{84}$ These $\mathrm{P} 1$ receptor subtypes exhibit different affinity to adenosine, distinct pharmacology and tissuespecific expression patterns. ${ }^{85}$ Briefly, $A_{1}, A_{2 A}$ and $A_{3}$ receptors have high affinity, hence they are activated by physiological level (nM) of extracellular adenosine. On the contrary, the activation of $A_{2 B}$ requires much higher adenosine concentration $(\mu M)$, which seems to be associated with pathological conditions such as hypoxia. ${ }^{84,86} A_{1}$ receptors are mostly localised in the nervous system, while the remaining three subtypes are diffusely expressed in a broad range of tissues including nervous system, spleen, colon, testis and others. ${ }^{87}$ Functionally, adenosine receptors are coupled with different $G$ proteins, modulating the activity of adenylate cyclase $(A C)$ in a positive or negative manner, thus affecting cytoplasmic cAMP. Both $A_{1}$ and $A_{3}$ receptors couple with $G_{i}$ protein, hence their activation suppresses $A C$ with subsequent decrease in cAMP level. In contrast, $A_{2 A}$ and $A_{2 B}$ are linked to $G_{s}$ protein which stimulates $A C .{ }^{85}$ Extracellular adenosine activates $A_{1}$ and $A_{2}$ receptors of cardiac myocytes and cardiac fibroblasts, respectively, leading to a downregulated CAMP production in cardiac myocytes but an increase of cAMP level in cardiac fibroblasts, thereby preventing myocardial hypertrophy and fibrosis. ${ }^{88}$ Apart of $\mathrm{AC}$, adenosine receptors regulate other effectors such as phospholipase $C$ (PLC) and mitogen-activated protein kinase (MAPK). ${ }^{89,90}$ PLC controls the production of diacyl glycerol (DAG), an endogenous activator of protein kinase $C$, and inositol 1,4,5-trisphosphate ( $\mathrm{Ins}_{3}$ ) that triggers $\mathrm{Ca}^{2+}$ release from endoplasmic reticulum (ER) $\mathrm{Ca}^{2+}$ store. Different adenosine receptors can form functional heteromeric complexes. For example, $A_{1}-A_{2 A}$ complex binds to both $G_{i}$ and $G_{s}$ proteins thus triggering opposite cAMP signals. The outcome of this bidirectional complex depends on the adenosine concentration. Low adenosine concentrations preferentially activate the $A_{1}$ subunit thus suppressing $A C$ activity. When adenosine is high, $A_{2 A}$ component is activated causing increase in cAMP production. ${ }^{91,92}$ Although the pathophysiological function of $\mathrm{P} 1$ receptors is extremely complex, adenosine is generally considered a "protective" signal against stress conditions, because adenosine decreases energy intense activities and enhances nutrient support. ${ }^{93}$ This property makes $\mathrm{P} 1$ receptors attractive targets for treatments of cardiovascular and other diseases. ${ }^{94}$

The P2 nucleotide receptor family is divided into two subfamilies, P2X (ATP-gated ion channels) and P2Y (metabotropic GPCRs). ${ }^{95}$ P2Y receptors are activated by several nucleotides including ATP, UTP, ADP and UDP, whereas P2X are only activated by ATP. In 1993, the first two P2Y receptors were cloned, and the first two $\mathrm{P} 2 \mathrm{X}$ receptors followed one year later. ${ }^{96-99}$ To date, seven $\mathrm{P} 2 \mathrm{X}\left(\mathrm{P} 2 \mathrm{X}_{1-7}\right)$ and eight $\mathrm{P} 2 \mathrm{Y}$ receptor members $\left(\mathrm{P} 2 \mathrm{Y}_{1}, \mathrm{P} 2 \mathrm{Y}_{2}, \mathrm{P} 2 \mathrm{Y}_{4}\right.$, $\mathrm{P}_{2} \mathrm{Y}_{6}, \mathrm{P}_{2} \mathrm{Y}_{11}, \mathrm{P}_{2} \mathrm{Y}_{12}, \mathrm{P}_{2} \mathrm{Y}_{13}$ and $\mathrm{P} 2 \mathrm{Y}_{14}$ ) are recognised. By analogy to $P 1$ adenosine receptors, $P 2 Y$ receptors couple to specific $G$ proteins thus differentially regulating downstream effectors including $A C$ and $P L C . P 2 Y_{1}, P_{2} Y_{2}, P_{2} Y_{4}$ and $P 2 Y_{6}$ receptors couple to $G_{q}$ protein, which activates PLC $\beta$ to induce $\mathrm{Ca}^{2+}$ release from ER. In contrast, $P 2 Y_{12}, P 2 Y_{13}$ and $P 2 Y_{14}$ couple to $G_{i}$ protein, which inhibits $A C$ to decrease cellular CAMP. $P 2 Y_{11}$ receptors are linked to both $G_{g}$ and $G_{s}$ and their activation triggers CAMP and $\mathrm{Ca}^{2+}$ signalling. ${ }^{100}$ As mentioned above, $\mathrm{P} 2 \mathrm{Y}$ receptors recognise not only ATP, but also other nucleotides as endogenous ligands, albeit with different efficacies. For instance, ADP is a more effective agonist at $\mathrm{P}_{2} \mathrm{Y}_{1}$ than ATP ${ }^{101}$. In contrast, $\mathrm{P}_{2} \mathrm{Y}_{2}$ has similar affinity for ATP and UTP, but is insensitive ER to ADP. ${ }^{102}$ Other P2Y receptors, including $\mathrm{P}_{2} \mathrm{Y}_{4}, \mathrm{P}_{2} \mathrm{Y}_{6}, \mathrm{P}_{2} \mathrm{Y}_{11}, \mathrm{P}_{2} \mathrm{Y}_{12}, \mathrm{P} 2 \mathrm{Y}_{13}$ and $\mathrm{P} 2 \mathrm{Y}_{14}$, prefer UTP, UDP, ATP, ADP, ADP and UDP-glucose, respectively. ${ }^{103}$
Additional chemical groups affect the potency of nucleotides at $\mathrm{P} 2 \mathrm{Y}$ receptors. At $\mathrm{P}_{2} \mathrm{Y}_{12}$, 2-methylthio-ADP (2-MeSADP) is more potent than ADP, but adenosine-5'-O-(2-thiodiphosphate) (ADP $\beta S$ ) is less potent. ${ }^{104}$ Protein orthologs in different species have distinct preference and affinity for agonists. For example, at human $\mathrm{P}_{2} \mathrm{Y}_{4}$ UTP is the most potent agonist, whereas at rat $\mathrm{P}_{2} \mathrm{Y}_{4}$ UTP and ATP are equipotent. ${ }^{105,106}$

P2X receptors are archetypal ATP-gated cation channels, ${ }^{107}$ with ATP being the only known physiological agonist. ${ }^{108}$ The family of $\mathrm{P} 2 \mathrm{X}$ receptors comprises seven members $\left(\mathrm{P} 2 \mathrm{X}_{1-7}\right)$ which assemble as homo- or heterotrimeric complexes. Among homotrimeric P2X receptors, $\mathrm{P} 2 \mathrm{X}_{1}$ shows the highest affinity for ATP being activated at ATP concentrations $<1 \mu \mathrm{M}$. $^{109}$ The least sensitive member is the $\mathrm{P}_{2} \mathrm{X}_{7}$ receptor which requires ATP concentrations in hundred micromolar range for activation. ${ }^{110}$ High ATP sensitivity is frequently accompanied with a rapid desensitisation, whereas less sensitive subtypes might show persistent activation. ${ }^{108}$ According to ATP sensitivity and desensitisation time, homotrimeric $\mathrm{P} 2 \mathrm{X}$ receptors are roughly classified into four subtypes. The first type includes $\mathrm{P} 2 \mathrm{X}_{1}$ and $\mathrm{P} 2 \mathrm{X}_{3}$ receptors, which are most sensitive to ATP and are rapidly desensitising. The second type includes $\mathrm{P} 2 \mathrm{X}_{2}$ and $\mathrm{P} 2 \mathrm{X}_{5}$ receptors with a lower ATP sensitivity and slower desensitisation. The $\mathrm{P} 2 \mathrm{X}_{4}$ receptor belongs to a third type having similar ATP sensitivity, but prolonged desensitisation compared with the second type. The last type, represented by $\mathrm{P} 2 \mathrm{X}_{7}$ receptors, shows the lowest ATP sensitivity and basically no desensitisation. ${ }^{111}$ The remaining member, the $\mathrm{P} 2 \mathrm{X}_{6}$ receptor is not classified into these groups because it lacks the ability to form homotrimeric receptors. ${ }^{112}$

Similar to $\mathrm{P} 2 \mathrm{Y}$ receptors, $\mathrm{P} 2 \mathrm{X}$ receptors can be activated by ATP analogues with different potencies. For activation of $\mathrm{P} 2 \mathrm{X}_{1}, \mathrm{P} 2 \mathrm{X}_{2}$, $\mathrm{P}_{2} \mathrm{X}_{3}$ and $\mathrm{P} 2 \mathrm{X}_{5}, 2$ 2-MeSATP is equipotent with ATP. On the contrary, 2-MeSATP is 10-fold less potent than ATP at P2X receptors, and 100 -fold less potent than ATP at $\mathrm{P} 2 \mathrm{X}_{7}$ receptors. ${ }^{113}$ Composition of heterotrimeric channels may be rather complicated. For example, $\mathrm{P} 2 \mathrm{X}_{1 / 2}$ heterotrimeric receptor is made of single $\mathrm{P} 2 \mathrm{X}_{1}$ and two $\mathrm{P} 2 \mathrm{X}_{2}$ subunits, whereas $\mathrm{P} 2 \mathrm{X}_{2 / 3}$ receptor is assembled from a single $\mathrm{P} 2 \mathrm{X}_{2}$ and two $\mathrm{P} 2 \mathrm{X}_{3}$ subunits. ${ }^{114,115}$ The $\mathrm{P} 2 \mathrm{X}_{2 / 4 / 6}$ receptor contains three different subunits, which is rarely observed for other P2X heterotrimers. ${ }^{116}$ This diversity of assembly confers to $\mathrm{P} 2 \mathrm{X}$ receptors a large repertoire of physiological functions in different tissues.

Several P2 receptor agonists and antagonists have been developed for the treatment of human diseases. The examples are many; for instance, thienotetrahydropyridines that irreversibly inactivate $\mathrm{P}_{2} \mathrm{Y}_{12}$ receptors are used as antithrombotic drugs. ${ }^{117}$ The $\mathrm{P}_{2} \mathrm{X}_{3}$ receptor antagonist, AF-219 is under phase 2 clinic trail for treating refractory chronic cough. ${ }^{118}$ The rationale underlying these successful trails is that ATP generally acts as a proinflammatory signal, hence antagonists targeting P2 receptors may help restrain inflammation. To the contrary, adenosine restricts the inflammatory response, suggesting a therapeutic potential for P1 receptor agonists as anti-inflammatory drugs. Neladenoson, an $A_{1}$ receptor agonist demonstrated positive results in the treatment of heart failure. ${ }^{119}$ Another promising application for modulators of purinergic signalling is a cancer therapy. Firstly, an inflammatory microenvironment has long been regarded as a hallmark of cancer. ${ }^{120}$ Secondly, tumour microenvironment is rich in ATP and adenosine. $^{121}$ Thirdly, a variety of purinergic receptors are expressed in a wide range of tumour types. ${ }^{122}$ Moreover, ATP and adenosine are critical for the energy metabolism of cancer cells. Following scattered reports on the anti-cancer activity of some purinergic agonists, ${ }^{123,124}$ several clinical trials have been initiated to test the effectiveness of $A_{2 A}$ antagonists, alone or in combination with other established chemotherapeutic or immune check-point blockers, in cancer therapy. ${ }^{125,126}$ In addition, the discovery that the tumour microenvironment is rich in 


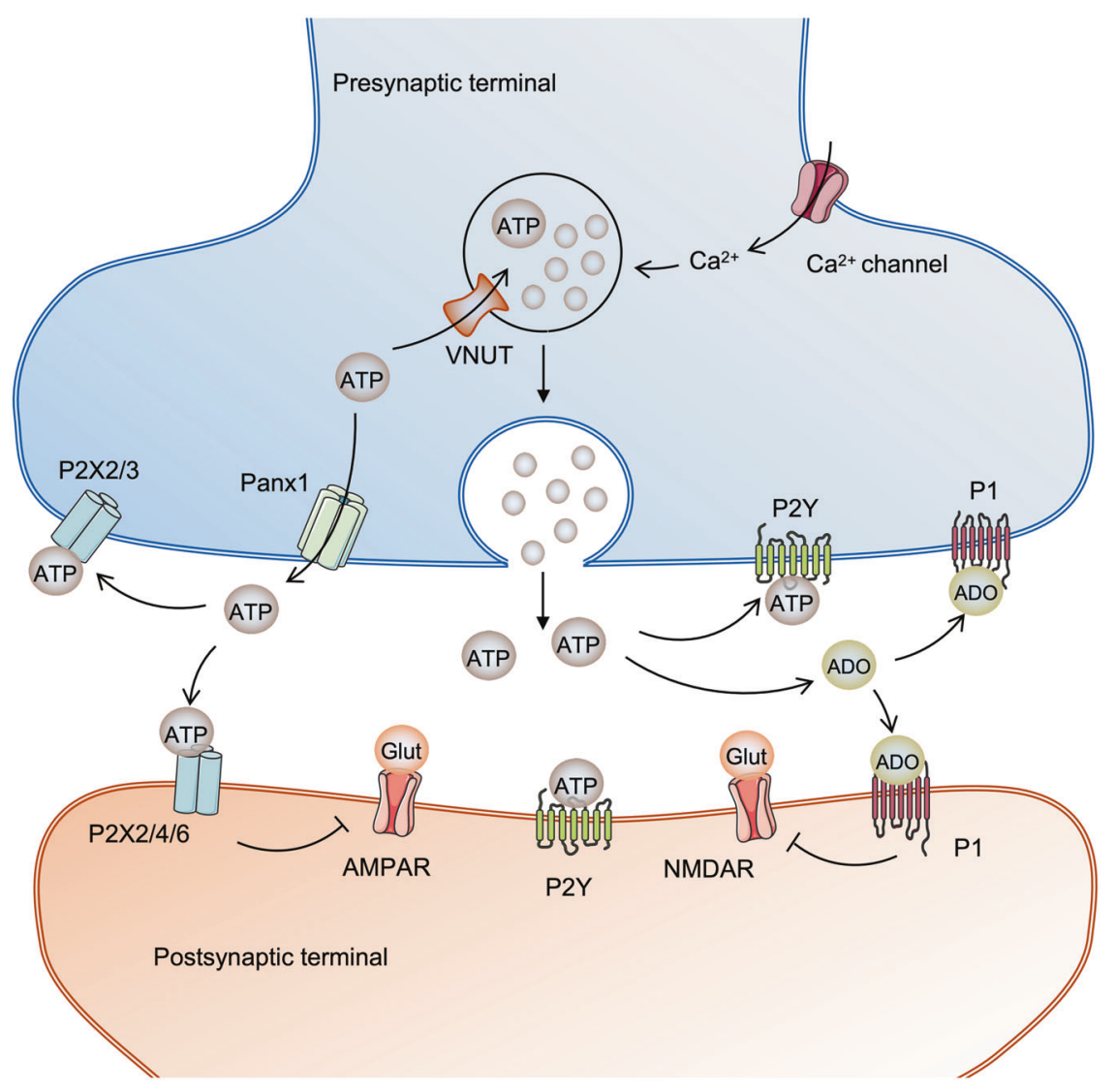

Fig. 4 Purinoceptors mediates neurotransmission in nervus system. In presynaptic terminal, ATP is enriched in vesicles by transporter VNUT and then released in a $\mathrm{Ca}^{2+}$-dependent manner, or exported by other channels such as Panx 1 independent of $\mathrm{Ca}^{2+}$. On one hand, extracellular ATP and its degradation product adenosine in turn activate purinoceptors in presynaptic terminal. This effect may regulate the release of other transmitters such as glutamate. On the other hand, extracellular ATP and adenosine can interact with postsynaptic purinoceptors, thereby regulating the excitability of neural cells. This event might also lead to the internalisation of AMPAR and NMDAR on postsynaptic membrane, leading to a decrease of glutamate-induced current. VNUT vesicular nucleotide transporter, Panx1 pannexin 1, AD adenosine, AMPAR AMPA receptor, NMDAR N-methyl-D-aspartate receptor

extracellular ATP $^{127}$ has fuelled trials designed to exploit this peculiar trait of tumours to confer selectivity to anticancer drugs. $^{128}$

\section{PURINERGIC NEUROTRANSMISSION IN NEURODEVELOPMENT AND THE PATHOGENESIS OF BRAIN DISEASES}

It is now well established that ATP is a bona fide neurotransmitter, contributing to the numerous functions of the nervous system (Fig. 4). ${ }^{129}$ In neuronal terminals ATP is accumulated within synaptic vesicles by vesicular nucleotide transporter VNUT/ SLC17A9. ${ }^{130}$ This transporter is widely expressed in the brain, and is central for ATP concentration $(>100 \mu \mathrm{M})$ in the lumen of vesicles. Genetic deletion of VNUT suppresses ATP exocytosis in PC12 chromaffin cell line, suggesting VNUT-mediated vesicular storage of ATP is critical purinergic transmission. ${ }^{130}$ The ATP-rich vesicles are secreted by exocytosis in a $\mathrm{Ca}^{2+}$ regulated manner; treatment with $\mathrm{Ca}^{2+}$ chelators or exocytosis inhibitors abolishes ATP release. ${ }^{131}$ This $\mathrm{Ca}^{2+}$-dependent exocytosis of ATP vesicles can be directly visualised by live cell imaging. ${ }^{132}$ Several nonvesicular ATP release mechanisms were also reported, including large transmembrane channels represented by $\mathrm{P} 2 \mathrm{X}_{7}$ receptors, connexins or pannexins. ${ }^{133,134}$ ATP is frequently released in combination with other transmitters. For instance, ATP has been found to be coreleased with noradrenaline (NA) and acetylcholine (ACh) in cortical synaptosomes ${ }^{135}$ and with glutamate in cortical slices ${ }^{134}$ ATP operating as a sole neurotransmitter has been found only in medial habenula. ${ }^{136}$
A fraction of released ATP activates $\mathrm{P} 2$ receptors in an autocrine/paracrine fashion. Remaining extracellular ATP undergoes hydrolysis to yield diphosphate nucleotides which activate several P2Y receptors, or is further broken down to produce adenosine thus activating P1 receptors. In this way, ATP or its metabolites stimulate para- or autocrinally purinergic receptors on the post- or presynaptic membrane, respectively. For example, ATP activates $\mathrm{P} 2 \mathrm{X}_{3}$ and $\mathrm{P} 2 \mathrm{X}_{2 / 3}$ receptors on the presynaptic membrane of spinal cord neurones, therefore regulating bladder micturition reflex. ${ }^{137}$ On the postsynaptic side, ATP-induced current can be evoked by the activation of $\mathrm{P} 2 \mathrm{X}_{2}, \mathrm{P} 2 \mathrm{X}_{4}, \mathrm{P} 2 \mathrm{X}_{6}$ ionotropic as well as $\mathrm{P} 2 \mathrm{Y}$ metabotropic receptors. ${ }^{138}$ As a cotransmitter, ATP may regulate other neurotransmission pathways. It has been shown that $\mathrm{P} 2 \mathrm{X}_{2}$ activation induces internalisation of glutamate receptor (AMPAR) on postsynaptic side, leading to a decrease of synaptic current in hippocampal neurones. ${ }^{139}$ Another glutamate receptor, N-methyl-D-aspartate receptor (NMDAR), is also regulated by $\mathrm{P} 2 \mathrm{X}$ receptors. ${ }^{140}$ In addition to the postsynaptic expression of glutamate receptors, the release of glutamate on the presynaptic membrane is regulated by both excitatory $\mathrm{P} 2$ receptors, including $\mathrm{P} 2 \mathrm{X}_{1}, \mathrm{P} 2 \mathrm{X}_{2 / 3}, \mathrm{P} 2 \mathrm{X}_{3}$, and inhibitory receptors $\mathrm{P} 2 \mathrm{Y}_{1}, \mathrm{P}_{2} \mathrm{Y}_{2}$ and $\mathrm{P}_{2} \mathrm{Y}_{4} \cdot{ }^{141}$ The bulk of extracellular ATP is readily degraded by ectonucleotidases to adenosine, which activates $P 1$ receptors and generally functions as an inhibitory signal. Among $\mathrm{P} 1$ receptors, $\mathrm{A}_{1}$ and $\mathrm{A}_{2 \mathrm{~A}}$ are two major subtypes responsible for purinergic signalling in the brain. ${ }^{142}$ For instance, activation of $A_{1}$ by adenosine results in a decrease of glutamate release and NMDAR expression on the 
presynaptic and postsynaptic membrane, respectively. ${ }^{143-145}$ Similarly, adenosine-mediated $A_{2 A}$ activation has been also found to inhibit glutamate release and NMDAR expression. ${ }^{146,147}$ Other details of purinergic neurotransmission have been extensively reviewed elsewhere. ${ }^{148}$

Purinergic signalling modulates embryonic neurodevelopment as well as neuroregeneration. Inner cell mass of blastocyst gives rise to the neural tube, in which progenitor cells differentiate to form peripheral and central nervous system, and these processes are largely regulated by purines and purinergic receptors. ${ }^{149}$ On

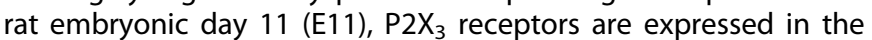
hindbrain neural tube to support the development of autonomic nervous system. ${ }^{150}$ Genetic ablation of $\mathrm{P}_{2} \mathrm{X}_{3}$ receptors in mice eliminates inward currents in vagal sensory neurons and impairs their ability to sense gastric distension. ${ }^{151}$ Transcriptomics of the embryonic rat brain showed that $P 2 Y_{1}$ receptors are hardly observed on E14 but are strongly expressed on E18, whereas $\mathrm{P}_{2} \mathrm{Y}_{4}$ maintains a comparable expression level throughout these days. ${ }^{152}$ In addition to this temporal regulation, expression of purinoceptors is region-dependent. On E9, $\mathrm{P} 2 \mathrm{X}_{5}$ receptors are expressed throughout the spinal cord. However, 2 days later these receptors are detected only in the ventral horn, which is relevant to the development of motor fibres. ${ }^{153}$ Another purinergic receptor, $\mathrm{P} 2 \mathrm{Y}_{2}$, is specifically expressed in the spinal motor nerves but not in the brain at E12. ${ }^{152}$ This purinergic receptor is colocalised with tyrosine receptor kinase $A$ (TrkA) during neuronal differentiation, knockout of the latter abrogates the axonal growth of sciatic nerve in response to the stimulation of ATPYS. ${ }^{154}$ As to the $\mathrm{P} 1$ adenosine receptors, administration of $\mathrm{P} 1$ antagonists to pregnant mice delays migration of certain neurones, thus affecting brain maturation and leading to an impaired memory in foetal mice. ${ }^{155}$ Mechanistically, purinergic transmission modulates proliferation, differentiation, and migration of neural stem cells (NSCs) and neural progenitor cells (NPCs), contributing to neurodevelopment in foetal nervous system and neuroregeneration in the adult brain. ${ }^{156}$ Neurogenesis in the adult brain occurs in two niches, in subgranular zone (SGZ) in hippocampal dentate gyrus and subventricular zone (SVZ) in the lateral ventricle. ${ }^{157}$ The radial stem astrocytes which populate these regions symmetrically divide into daughter NSCs with self-renewal capabilities and asymmetrically into NPCs with highly proliferative properties; these latter give rise to neuroblasts. Several purinergic receptors regulate adult neurogenesis. For instance, the expression of $\mathrm{P}_{2} \mathrm{X}_{7}$ receptors has been detected in both embryonic SGZ/SVZ and in the adult hippocampus. ${ }^{158}$ In embryonic NSCs, activation of $\mathrm{P}_{2} \mathrm{X}_{7}$ receptors accelerates cell proliferation and inhibits differentiation. ${ }^{159}$ In the adult hippocampus, to the contrary, $\mathrm{P} 2 \mathrm{X}_{7}$ receptors suppress the growth of NPCs and promote the differentiation into neurones and astrocytes. ${ }^{160}$ This effect may contribute to the damage repair in the adult brain by restricting inappropriate cell proliferation and facilitating neuronal production. Metabotropic $\mathrm{P}_{2} \mathrm{Y}_{1}$ receptors, stimulate proliferation and migration of neural progenitors, but do not affect their differentiation. ${ }^{161}$ In a $\mathrm{P}_{2} \mathrm{Y}_{1}$ receptor knockout mouse model, the downregulation of $\mathrm{P}_{2} \mathrm{Y}_{1}$ receptors was a prerequisite for the production of neuroprotective astrocytes during brain repair. ${ }^{162}$ In the presence of neurotrophins, ATPYS-mediated TrkA phosphorylation leads to neuronal differentiation in wild-type, but not in $\mathrm{P}_{2} \mathrm{Y}_{2}$ receptor-null mice, indicating that $\mathrm{P}_{2} \mathrm{Y}_{2}$ receptor is required for neurotrophininduced regeneration. ${ }^{154}$ Elimination of unnecessary neural cells is a vital process during neurodevelopment, in which several purinoceptors including $\mathrm{P} 2 \mathrm{X}_{4}, \mathrm{P} 2 \mathrm{X}_{7}, \mathrm{P}_{2} \mathrm{Y}_{2}$ and $\mathrm{P} 2 \mathrm{Y}_{6}$ receptors are involved. $^{163-166}$ Modulation of neuronal apoptosis is largely attributed to excessive $\mathrm{Ca}^{2+}$ release from the $E R$, the process controlled by $\mathrm{PLC} / \mathrm{InsP}_{3} / \mathrm{InsP}_{3}$ receptor axis downstream of purinoceptors. ${ }^{167}$

Aberrant purinergic transmission in the brain contributes to the pathogenesis of neurodegenerative disorders (i.e. Alzheimer's disease, Parkinson's disease, Huntington's diseases, etc.) and neuropsychiatric diseases (i.e. depression, anxiety, addiction, etc.) (Table 1). ${ }^{168-171}$ Alzheimer's disease (AD) is manifested by impaired cognition and memory and it is currently incurable. Deposition of $\beta$-amyloid aggregates is generally considered to be the primary cause of neuronal loss and a decreased level of ACh in brain, whereas other factors such as hyperphosphorylation of tau protein and disturbed metabolism of metal ion are also proposed. Numerous studies focusing on purinergic signalling provide another explanation for $A D$. As mentioned above, two $P 1$ receptors $A_{1}$ and $A_{2 A}$ are mostly responsible for the effects of adenosine in brain. Generally, the roles of $A_{1}$ and $A_{2 A}$ in $A D$ progression seem to be context-dependent, with both protective and deleterious consequences have been observed in the treatment of P1 agonists or antagonists. In $A D$ patients, the expression of $A_{1}$ receptors is downregulated in the hippocampus, whereas the expression of $A_{2 A}$ is upregulated in the periphery. ${ }^{172,173}$ Mechanistic study revealed that $A_{1}$ receptors are co-localised with $A \beta$ aggregates, and activation of $A_{1}$ receptors leads to phosphorylation of PKC and ERK, which stimulates the production of soluble $A \beta .^{174}$ In contrast, genetic ablation of $A_{2 A}$ receptors in mice protects against $A D$ phenotypes, while optogenetic activation of this purinoceptor is sufficient to induce memory deficits. ${ }^{175,176}$ These findings suggest that $A_{1}$ and $A_{2 A}$ may exert opposite functions during $A D$ progression. Epidemiological studies indicate that caffeine, the non-selective antagonist of both $A_{1}$ and $A_{2 A}$ receptors, effectively improves cognitive function and decreases the risk of $A D .^{177,178}$ This observation implies that the deleterious effects of $A_{2 A}$ receptor may override the protective effects of $A_{1}$ receptor during $A D$ progression. Moreover, it has been reported that caffeine keeps blood-brain barrier intact, thus preventing $\beta$-amyloid deposition in brain. ${ }^{179}$ Given that the permeability of blood-brain barrier relies on multiple factors, the protective effect of caffeine might be attributed to other potential targets in addition to P1 receptors. Dysregulated ATP metabolism due to impaired mitochondrial function, for example, is one of the common characteristics in AD brain. ${ }^{180}$

Several studies demonstrated that $\mathrm{P} 2 \mathrm{X}_{7}$ receptor inhibition presents a neuroprotective effect in AD animal models. ${ }^{181,182}$ In rat hippocampus, $\beta$-amyloid aggregates have been shown to colocalise with $\mathrm{P}_{2} \mathrm{X}_{7}$ receptors. ${ }^{83}$ This co-localisation coincides with upregulated expression of $\mathrm{P}_{2} \mathrm{X}_{7}$ receptors, arguably linked to the production of reactive oxygen species (ROS). ${ }^{184}$ Mechanistically, $\mathrm{P}_{2} \mathrm{X}_{7}$ receptors promote $\beta$-amyloid deposition through a-secretase. Amyloid precursor protein (APP) is cleaved by three family members of secretase, namely $\alpha_{-}^{-}, \beta-$, and $\gamma^{- \text {secretase with }}$ different cleavage sites. Cleavage by a-secretase produces soluble fragment sAPP, which is harmless. Alternatively, $\beta$ - and $\gamma$-secretase generate toxic $\beta$-amyloid which contributes to formation of senile plaques. Activation of $\mathrm{P}_{2} \mathrm{X}_{7}$ receptors was shown to inhibit the activity of a-secretase through activating glycogen synthase kinase 3 (GSK-3), leading to $A \beta$ deposition in mice. ${ }^{185}$ However, opposite findings have been also reported demonstrating that $\mathrm{P}_{2} \mathrm{X}_{7}$ receptors activate a-secretase via modulation of MAPK pathway to produce SAPP. ${ }^{186}$ These contradictory results indicate that the role of $P 2 X_{7}$ receptors in $A D$ is yet to be characterised.

Depression is a neuropsychiatric disease characterised by decreased self-esteem and interest loss, with a low quality of personal life in aspects of sleeping, diet and general health. Epidemiological studies indicate that moderate coffee intake reduces the risk of depression, whereas excessive consumption may worsen the situation. ${ }^{187,188}$ This observation highlights possible involvement of $A_{1}$ and $A_{2 A}$ adenosine receptors. Administration of $Z M$ 241385, an inhibitor of $A_{2 A}$ receptor, decreases the immobility and isolation time in a rat depression model, indicating that activation of $A_{2 A}$ receptor contributes to depressive behaviour. ${ }^{189}$ Consistently, rats overexpressing $A_{2 A}$ receptor demonstrate depressive phenotypes. ${ }^{190}$ In contrast, stimulation of $A_{1}$ receptor exhibits antidepressant effects. 


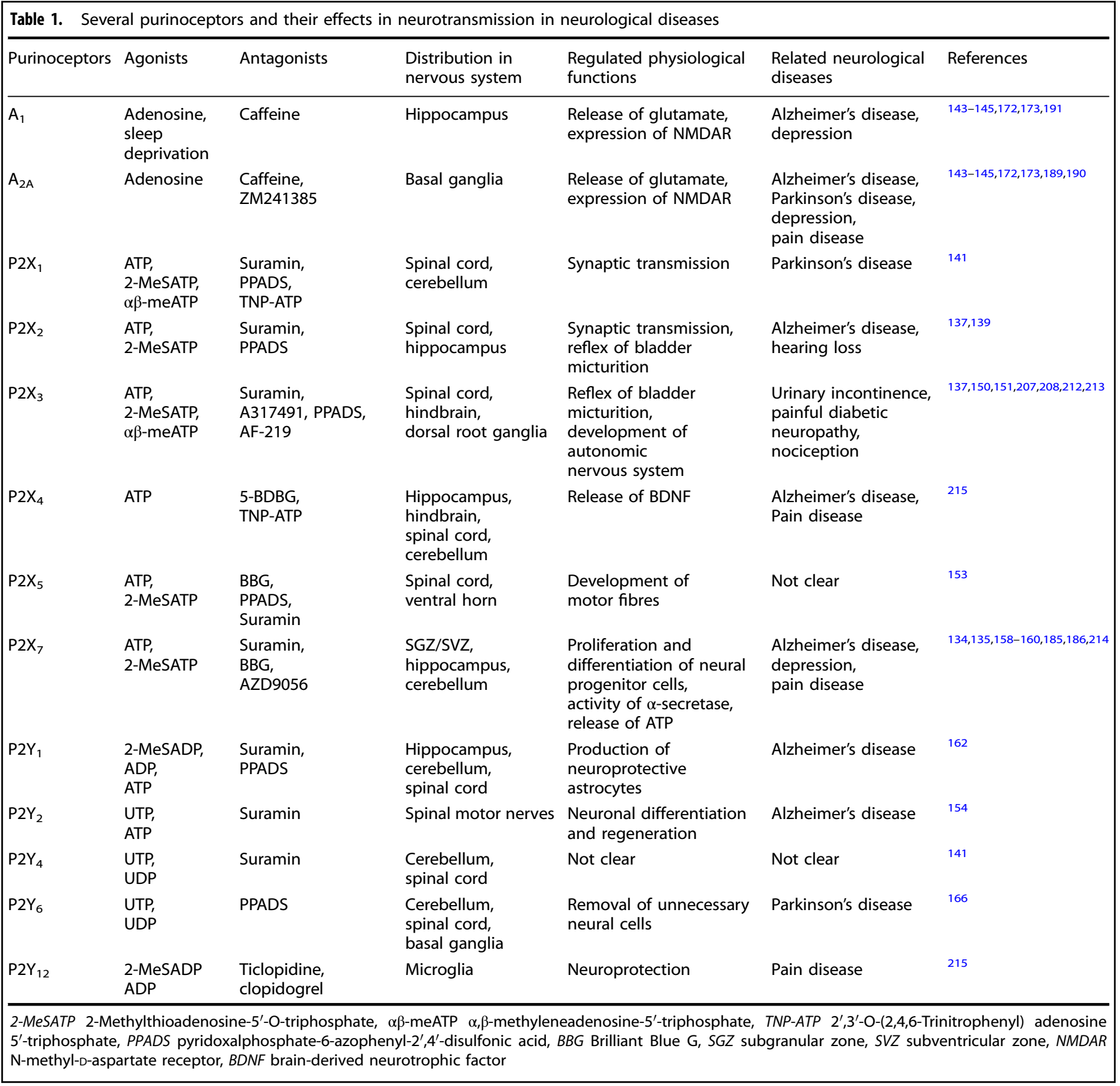

Activation of $A_{1}$ receptors increases travel distance, whereas knockout of $A_{1}$ receptors leads to immobility and other depressive behaviours in mice. ${ }^{191}$ Sleep deprivation, a widely used method to temporally relief depression, acts through activating $A_{1}$ receptors. ${ }^{192}$ Consequently, moderate caffeine consumption predominantly inhibits $A_{2 A}$ receptors to with anti-depressant effect, whereas high dose of caffeine inhibits $A_{1}$ receptors thus worsening depressive symptoms. This hypothesis is supported by the finding that antagonists for $A_{2 A}$, but not for $A_{1}$ receptors, potentiate effects of classic antidepressants. Two antidepressant agents, agomelatine and tianeptine, were tested in combination with selective inhibitor of $A_{1}$ receptors (DPCPX) and $A_{2 A}$ receptors (DMPX). Such combination revealed that co-treatment with DMPX, but not with DPCPX, increases the concentration of agomelatine and tianeptine in the brain thus potentiating their antidepressant effect. ${ }^{193}$ The P2 purinoceptors are also involved in depression. Psychological stress induces the release of ATP, activating $\mathrm{P} 2 \mathrm{X}_{7}$ receptors thus leading to depressive behaviours in mice; the anxiety behaviour can be reversed by administration of $\mathrm{P}_{2} \mathrm{X}_{7}$ receptor antagonist. ${ }^{194}$ Genetic deletion of $\mathrm{P} 2 \mathrm{X}_{7}$ receptor is anti-depressive in mice, and increases the efficacy of antidepressant drugs. ${ }^{195}$ Single nucleotide polymorphisms (SNPs) in $\mathrm{A}_{2 \mathrm{~A}}$ and $\mathrm{P} 2 \mathrm{X}_{7}$ receptor genes are linked to neuropsychiatric pathology. For example, the $T$ genotype at rs2298383 SNP in $A_{2 A}$ receptor predicts lower risk of depression compared to the CC or CT genotypes. ${ }^{196}$ The rs 2230912 polymorphism also causes a Gln460Arg mutation in $\mathrm{P} 2 \mathrm{X}_{7}$ receptor, which is associated with depression. ${ }^{197}$ These SNPs are believed to serve as potential indicators for early risk assessment of depressive disorders. Notably, several enzymes and metabolites of the purinergic transmission are also potential biomarkers for depression. It has been found that increased activities of adenosine 
deaminase (ADA) and xanthine oxidase (XO), as well as elevated level of xanthine and hypoxanthine correlate with a higher risk of depression. ${ }^{198}$ This evidence indicates that enzymes and metabolites involved in purine metabolism, together with purinoceptors, profoundly influence the pathophysiological function of nervous system.

\section{PURINERGIC TRANSMISSION IN MECHANOSENSORY TRANSDUCTION AND PAIN}

In 1977, the link between injection of ATP and other purines into human skin blisters and initiation of pain was discovered. ${ }^{199}$ Since then, a series of studies proved that activation of $\mathrm{P} 2 \mathrm{X}$ receptors leads to pain-related defensive behaviours in animals. ${ }^{200-202}$ Acupuncture, an ancient medicinal codex developed in China over 4000 years, is used to relieve pain worldwide. Injection of $A_{1}$ receptor agonist mimics the analgesic effect of acupuncture, suggesting it works through activating $A_{1}$ receptors. ${ }^{203-205}$ To the contrary, $\mathrm{P} 2$ receptors commonly potentiate pain signals. The $\mathrm{P} 2 \mathrm{X}_{3}$ receptor is the best characterised pain-related $\mathrm{P} 2$ receptor; which is predominantly expressed in small sensory neurones at dorsal root ganglia (DRG). Elimination of $\mathrm{P} 2 \mathrm{X}_{3}$ receptors by toxin leads to a blunted response to acute pain in a rat model. ${ }^{206}$ In the context of human diseases, $\mathrm{P} 2 \mathrm{X}_{3}$ receptor is also associated with painful diabetic neuropathy (PDN). Electroacupuncture decreases PKCmediated upregulation of $\mathrm{P}_{2} \mathrm{X}_{3}$ receptors in DRG, which attenuates neuropathic pain and relieves PDN. ${ }^{207,208}$

Though positive effects have been observed in clinic, acupuncture and electroacupuncture are invasive procedures which do not fully satisfy the requirements of evidence-based medicine.
Therefore, selective agonists (mostly for P1 receptors) and antagonists (mostly for P2 receptors) have been considered as promising analgesic agents. ${ }^{93,209}$ For example, the agonist of $A_{3}$ receptors IB-MECA has significant pain-relieving effects in a mouse model. ${ }^{210}$ However, not all P1 receptor agonists with analgesic properties in animal proved their worth in clinical trials (the WAG 994 being an example. ${ }^{211}$ As to antagonists of $P 2$ receptors, A317491 a selective inhibitor of $\mathrm{P} 2 \mathrm{X}_{3}$ and $\mathrm{P} 2 \mathrm{X}_{2 / 3}$ receptors, is capable of relieving acute and chronic nociception in rat models, ${ }^{212,213}$ In addition, several P2 antagonists demonstrated efficacy in clinical trials. The $\mathrm{P}_{2} \mathrm{X}_{7}$ receptor antagonist AZD9056 has been shown to relief pain without obvious side effects in a phase II study. ${ }^{214}$ Similarly, antagonists for other P2 receptors including $\mathrm{P}_{2} \mathrm{X}_{4}$ and $\mathrm{P}_{2} \mathrm{Y}_{12}$ receptors demonstrated analgesic effects. $^{215}$

\section{PURINERGIC TRANSMISSION INTEGRATES IMMUNE SYSTEM AND MODULATES INFLAMMATORY RESPONSES}

Gout is classified as a rheumatic immune disease, and pain is frequently companied by local inflammation. ${ }^{216}$ DNA, which is composed of purines, activates innate immunity when being translocated from nucleus or mitochondria into cytoplasm. ${ }^{217}$ This suggests a critical role for purinergic transmission in the regulation of immune system and inflammatory responses (Fig. 5). Purinergic receptors are expressed in nearly all kinds of immune cells. For instance, neutrophils express all four adenosine receptors and several $\mathrm{P} 2$ receptors including $\mathrm{P} 2 \mathrm{X}_{1}, \mathrm{P} 2 \mathrm{X}_{7}, \mathrm{P} 2 \mathrm{Y}_{2}$ and $\mathrm{P} 2 \mathrm{Y}_{14}$ receptors. $^{218}$ In addition, several ectoenzymes such as CD39 and CD73 are expressed in immune cells; these enzymes regulate

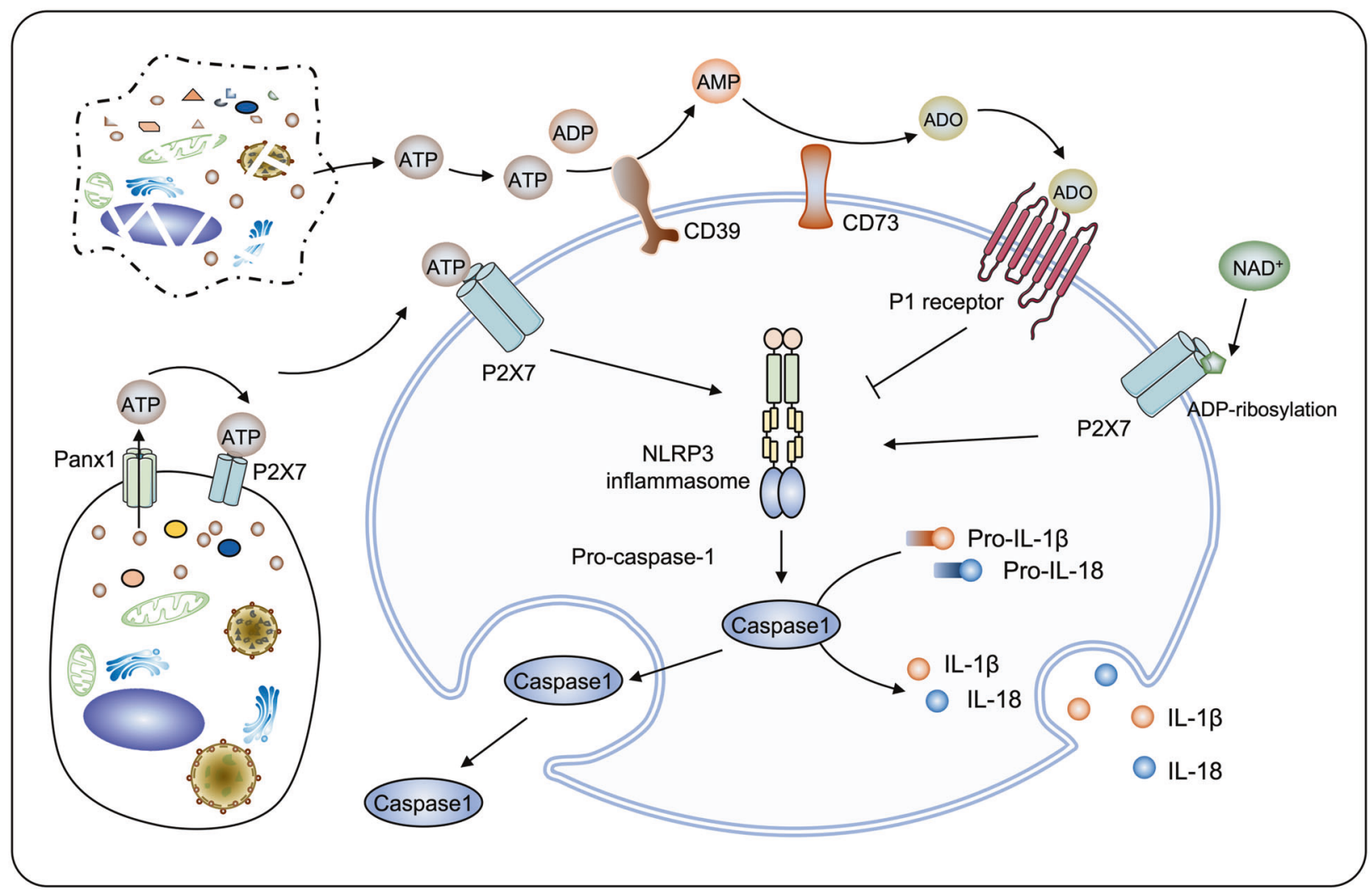

Fig. 5 Purinergic signalling regulates immune and inflammatory responses. Besides necrotic cells, extracellular ATP can be released from living cells through Panx 1 channel. Extracellular ATP activates P2X $X_{7}$ receptors, which subsequently activate NLRP3 inflammasome to induce the cleavage of pro-caspase-1. This effect leads to the maturation and release of caspase-1 thus initiating an immune or inflammatory response. Alternatively, extracellular ATP is ready to be degraded into adenosine (ADO) by ectoenzymes such as CD39 and CD73. The production of adenosine generally represses immune and inflammatory through binding with $\mathrm{P} 1$ receptors. In addition, $\mathrm{P} 2 \mathrm{X}_{7}$ can be activated by ADP-ribosylation using $\mathrm{NAD}^{+}$as an ADP-ribose donor 
immune response through the production of adenosine from ATP. ${ }^{219}$ In general, ATP serves as a danger signal that activates immune cells, while adenosine attenuates inflammatory responses. ${ }^{220}$ Conceptually, extracellular ATP activates P2 receptors to initiate the immune response; subsequently ATP is converted to adenosine by CD39, CD73 and other ectoenzymes, leading to the activation of $\mathrm{P} 1$ receptors which contain inflammation. This model is supported by a large body of evidence. For example, CD39 and CD73 expressed in regulatory $T$ cells (Tregs) convert extracellular ATP to adenosine, which suppresses the function of $T$ effector cells. ${ }^{205}$ The recent finding that CD39 knockout mice possess enhanced immunity due to increased extracellular ATP and decreased adenosine, thus producing more $\mathrm{CD} 8^{+} \mathrm{T}$ in their spleen to resist bacterial infection further corroborates this model. ${ }^{221}$ Given the vital role of extracellular ATP in the onset of immune response, a longstanding question is that how ATP is released from the cells under infectious lesions or tissue-damaging conditions. First, ATP derives from necrotic cells. ${ }^{222}$ Second, ATP can be also released through several types of channels, such as pannexin 1 (Panx1). ${ }^{223}$ In contrast to necrosis, ATP released by Panx 1 channel is regulated, for certain stimuli such as hypoxia induces Panx1 to form an ATP conduit, thereby accelerating ATP efflux. 224

Functional $\mathrm{P} 2 \mathrm{X}_{7}$ receptor is a trimeric complex with a variable conformation switches between open (ATP-bound) and closed states, which is one of the most intensively studied purinergic receptors that shapes immune responses. ${ }^{225,226}$ Mounting evidence suggests that $\mathrm{P} 2 \mathrm{X}_{7}$ receptors control cytokine release and immune cell activation, thus modifying immune and inflammatory

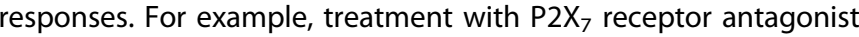
Brilliant Blue G (BBG) markedly decreases the level of plasma TNF$a$ in rats, thus suppressing the lipopolysaccharide (LPS)-induced febrile response. ${ }^{227}$ Inhibition of $\mathrm{P}_{2} \mathrm{X}_{7}$ receptors by periodateoxidised ATP relieved allograft rejection in a cardiac transplantation mouse model; this relief being mediated by reduced T-cell activation. ${ }^{228}$ Stimulation of $\mathrm{P}_{2} \mathrm{X}_{7}$ receptors activates NLRP3 inflammasome, thereby regulating immune and inflammatory responses. Inhibition of $\mathrm{P}_{2} \mathrm{X}_{7}$ receptors prevents the activation of NLRP3, leading to a decreased caspase- 1 cleavage and reduced sterile liver inflammation. ${ }^{229}$ Arguably there is a physical interaction between $\mathrm{P}_{2} \mathrm{X}_{7}$ receptors and NLRP3, which explains a molecular mechanism of $\mathrm{P}_{2} \mathrm{X}_{7}$ receptor-induced NLRP3 activation. ${ }^{230}$ Activated NLRP3 promotes the release of IL-1 $\beta$ through cleaved caspase-1, thereby leading to inflammation. ${ }^{231}$ In $\mathrm{P}_{2} \mathrm{X}_{7}$ receptor knockout mice, the release of IL-1 $\beta$ from peritoneal macrophages is largely blocked, indicating that $\mathrm{P} 2 \mathrm{X}_{7}$ receptors are required for IL-1 $\beta$ secretion. ${ }^{232}$ The $\mathrm{P}_{2} \mathrm{X}_{7}$ receptor is the most potent activator of the NLRP3 inflammasome so far known, and therefore a most potent stimulator of mature IL-1 $\beta$ release. However, direct agonists of the NLRP3 inflammasome may trigger $\mathrm{IL}-1 \beta$ release in a $\mathrm{P} 2 \mathrm{X}_{7}$ receptor-independent fashion. ${ }^{233}$ Genetic deletion of $\mathrm{P}_{2} \mathrm{X}_{7}$ receptor in mice did reduce, but never completely abrogated the release of IL- $1 \beta .{ }^{234}$ In addition to IL$1 \beta$, another cytokine released by NLRP3 is IL-18, and involvement of $\mathrm{P}_{2} \mathrm{X}_{7}$ receptor in IL-18 release has been documented. ${ }^{235}$

Other purines that accumulate at inflammatory sites, i.e. oxidised nicotinamide adenine dinucleotide $\left(\mathrm{NAD}^{+}\right)$, may activate the $\mathrm{P} 2 \mathrm{X}_{7}$ receptor synergistically with ATP, at least in the mouse. ${ }^{236} \mathrm{NAD}^{+}$provides an ADP-ribose that is covalently transferred to protein substrates, which reaction is catalysed by the ADP-ribosyltransferase (ART). This posttranslational modification, known as ADP-ribosylation, occurs at the extracellular domain of $\mathrm{P}_{2} \mathrm{X}_{7}$ receptor to initiate an inflammatory response. ${ }^{237}$ Mounting evidence suggests that $\mathrm{NAD}^{+}$not only provide chemical group for ADP-ribosylation, but also mediate immune and inflammatory responses, at least partially, independent of the ADP-ribosylation. $\mathrm{NAD}^{+}$shares considerable similarities with ATP in terms of immunity modulation. Firstly, $\mathrm{NAD}^{+}$and ATP are both defined as danger signals. ${ }^{238-240}$ Secondly, both are released from necrotic or damaged cells. ${ }^{241,242}$ Thirdly, both extracellular NAD ${ }^{+}$ and ATP can accumulate at high concentration at the injury sites. ${ }^{243,244}$ Moreover, $\mathrm{NAD}^{+}$itself is an agonist at $\mathrm{P}_{2} \mathrm{Y}_{11}$ receptor. ${ }^{245}$ This evidence indicates that $\mathrm{NAD}^{+}$probably activates immune responses similarly to ATP. Indeed, intravenous injection of $\mathrm{NAD}^{+}$significantly decreased the population of $\mathrm{CD}^{+}{ }^{+} \mathrm{FoxP}^{+}$ Tregs, thereby promoting an antitumour response in vivo. ${ }^{237}$. On the contrary, inhibition of NAD synthetase NAMPT has been shown to decrease cytokine release, which can be used to attenuate acute intestinal inflammation. ${ }^{246}$

\section{PURINERGIC SIGNALLING REGULATES TUMOUR DEVELOPMENT AND PROGRESSION}

Inflammatory and immunosuppressive microenvironment is a hallmark of cancer. ${ }^{247}$ Given the key roles of ATP and adenosine as pro-inflammatory and anti-inflammatory agents, respectively, this suggests a fundamental role of purinergic signalling in tumour development and progression (Fig. 6). Tumour microenvironment is rich in adenosine and ATP. ${ }^{10,248}$ It has been demonstrated that ATP accumulates at tumour interstitium at hundreds of micromolar while being nearly undetectable in the healthy samples. ${ }^{249}$ As discussed in the previous section, ATP controls immune cells, and accumulation of ATP triggers an antitumour immunity thus inhibiting tumourigenesis. ${ }^{10}$ Several types of $\mathrm{P} 2$ receptors are involved in the suppression of tumour growth, including $\mathrm{P} 2 \mathrm{X}_{5}$, $\mathrm{P}_{2} \mathrm{X}_{7}, \mathrm{P} 2 \mathrm{Y}_{1}, \mathrm{P}_{2} \mathrm{Y}_{2}$ and $\mathrm{P} 2 \mathrm{Y}_{11}$ receptors. ${ }^{250,251}$ For example, $\mathrm{P} 2 \mathrm{X}_{5}$ receptors contribute to the cytotoxic effects of $\mathrm{T}$ cells and suppression of chronic myeloid leukaemia. ${ }^{252,253}$ In contrast, knockout of $\mathrm{P}_{2} \mathrm{X}_{7}$ receptors decreases the population of $\mathrm{CD}^{+}$ cytotoxic T cells. ${ }^{254}$ Therefore, ATP enrichment in tumour microenvironment seems to be an intrinsic antitumour mechanism induced by immune system. However, P2 receptors are found not only in immune cells, but also in cancer cells, making one wondering why tumour cells express "suicidal" molecules. ${ }^{255}$ This concern is even more pronounced due to the fact that extracellular ATP not only leaks from necrotic cells, but derives from active secretion associated with cancer cell metabolism. ${ }^{256,257}$ It appears that the antitumour immunity is potentiated at a high level of ATP (supplied pharmacologically), whereas a small increase of ATP (released endogenously) promotes proliferation of cancer cells. ${ }^{258,259}$ Indeed, overexpression or downregulation of $\mathrm{P}_{2} \mathrm{X}_{7}$ receptors has been shown to facilitate or suppress tumour growth, respectively. ${ }^{260}$ Apart from the growth-promoting function, low levels of ATP may also result in tumourigenesis through the release of immunosuppressive cytokines, such as IL-10. ${ }^{261}$ This evidence indicates that expression of certain P2 receptors provides advantages for tumours but also imply a pharmacologic approach towards cancer immunotherapy. According to this approach, ATP infusion has been shown to relieve the loss of weight and restore muscle strength in lung cancer patients. ${ }^{262,263}$

Adenosine similarly accumulates in tumour microenvironment and affects the development and progression of cancer. Extracellular adenosine largely derives from ATP breakdown, which is catalysed by ectoenzymes including CD39 and CD73. All four subtypes of P1 receptors are expressed in tumour cells. For instance, $A_{1}$ receptors is overexpressed in renal cell carcinoma (RCC), and treatment with $A_{1}$ receptors antagonist DPCPX inhibits RCC progression. ${ }^{264}$ Both $A_{2 A}$ and $A_{2 B}$ receptors highly expressed in neuroendocrine tumours promote proliferation of cancer cells. ${ }^{265}$ Activation of $A_{3}$ receptors in glioblastoma increases the migration and invasion of cancer cells under hypoxia. ${ }^{266}$ As an immunosuppressive factor, adenosine supports tumour growth, at least partially. through repressing the antitumour immune responses. Genetic ablation or pharmacologic inhibition of $A_{2 A}$ receptors restores the antitumour activity of $T$ cells, suggesting potential strategy for the cancer immunotherapy. ${ }^{267,268}$ Given that ectoenzymes are largely responsible for the production 


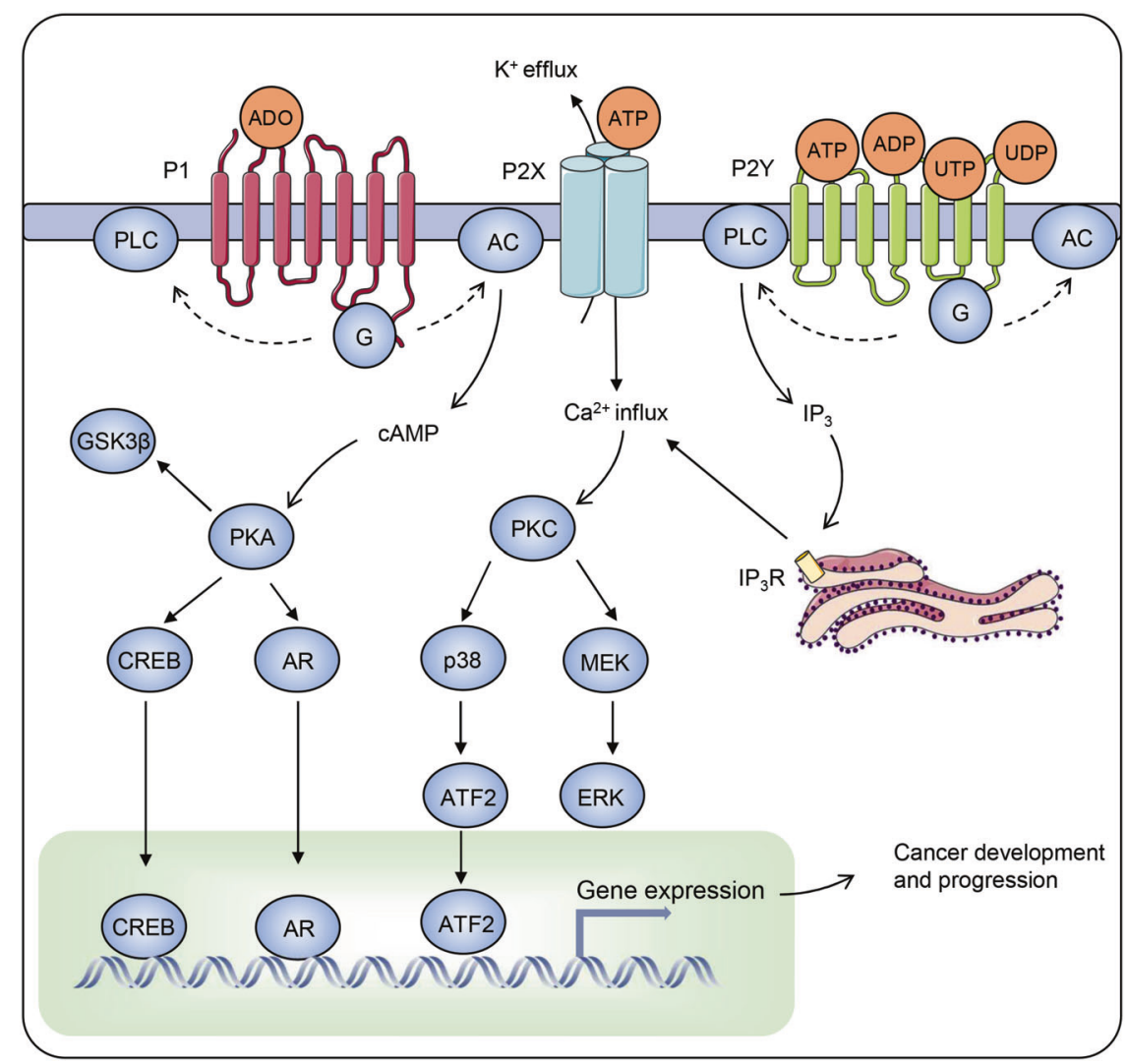

Fig. 6 Purinergic signalling involved in the initiation and progression of cancer. Tumour microenvironment is rich in purines, including adenosine (AD) and other nucleotides. A panel of purinergic receptors are expressed in tumour cells to receive these extracellular purinergic signals. Activation of P1 and P2Y receptors leads to an altered activity of adenylate cyclase or phospholipase C (PLC) by coupling different G proteins $(\mathrm{G})$, whereas activation of $\mathrm{P} 2 \mathrm{X}$ receptors generates ion fluxes. These events change the level of several secondary messengers, such as CAMP, $\mathrm{Ca}^{2+}$ and $\operatorname{InsP}_{3}$. InsP $\mathrm{P}_{3}$ binds to the $\mathrm{InsP}_{3}$ receptors on endoplasmic reticulum (ER), leading to the release of $\mathrm{Ca}^{2+} \mathrm{from}_{\mathrm{ER}}$. Thus, numerous proteins are regulated by these secondary messengers, including PKA, PKC, GSK3 $\beta$, CREB, androgen receptor (AR), MEK, p38, ERK and ATF2. Among them are several transcription factors such as CREB, AR and ATF2, which induce a cancer-related transcription programme

of adenosine in tumour microenvironment, suppression of these ectoenzymes (for example of CD73) has been shown to have considerable effects to enhance antitumour immune responses, and CD73-null mice are resistant to tumourigenesis. ${ }^{269,270}$ Adenosine seems to regulate cancer development in a dose-dependent manner in this resembling ATP. Endogenous adenosine converted from extracellular ATP promotes the migration of breast cancer cells, whereas exogenous adenosine or $A_{3}$ receptors agonist IB-MECA suppresses their mobility. ${ }^{271}$

Purinergic receptors modulate the activity of downstream signalling cascades, thereby playing a role in cancer development and progression. Adenylate cyclase and PLC are two major effectors that couple with purinergic receptors and initiate downstream signallings. Alteration of CAMP was found in numerous malignancies. ${ }^{272}$ For instance, an increase in CAMP is associated with hepatocellular carcinoma (HCC). ${ }^{273}$ In contrast, the level of cAMP is decreased in lymphoma and ovarian cancer. ${ }^{274,275}$ Mechanistically, cAMP binds to the regulatory (inhibitory) subunits of protein kinase A (PKA), leading to its activation. The involvement of PKA in cancer has been extensively reviewed elsewhere. ${ }^{276,277}$ Another downstream effector, PLC, catalyses the production of diacyl glycerol (DAG) and InsP $\mathrm{P}_{3}$ which both affect tumourigenesis. ${ }^{278}$ These secondary messengers play central roles in the signal transduction, linking purinergic signalling to other pathways especially those involved in embryonic and tumour development (i.e. Hippo, Wnt, Hedgehog, Notch and TGF- $\beta$ ). ${ }^{279-283}$ Genetic variations in the loci of purinergic receptors were demonstrated to have a prognostic value for tumour chemotherapy. Loss of $\mathrm{P} 2 \mathrm{X}_{7}$ receptors allele promotes metastasis in anthracycline-treated breast cancer patients due to a deficient antitumour immunity compared with those patients harbouring a wild-type $\mathrm{P} 2 \mathrm{X}_{7}$ gene. ${ }^{284}$

\section{PREVENTION AND THERAPY OF PURINE-RELATED DISEASES BY DIETARY AND HERBAL INTERVENTIONS}

Hyperuricemia induced by dysregulation of purine metabolism is associated with metabolic syndrome, which is also characterised by other features including obesity, hyperglycaemia, hypertension, hyperlipidemia and hyperinsulinemia. Similar to other metabolic syndrome manifestations, purine-related diseases are closely associated with the modern lifestyle. ${ }^{285}$ A 12 -year perspective study suggested that intake of meat and seafoods increase the risk of gout to 1.41 and 1.51, respectively. In contrast, supplement with dairy products decreases the risk to $0.56 .^{286}$ Although high abundance of purines in certain foods contributes to their propensity to induce gout, intake of purine-rich vegetables is not a risk factor. ${ }^{287}$ This difference might be attributed to the different bioavailability of purine derivatives from an animal or plant origin. ${ }^{288}$ Moreover, vegetables are beneficial for cardiovascular diseases and obesity, which are linked to aberrant purine metabolism. ${ }^{289,290}$ Therefore, vegetarian diet is beneficial regardless the purine content. Meat restriction calls for alternative protein sources, with legumes and dairy products are ideal choices. Inverse correlation between legume consumption and hyperuricemia were observed in independent cohorts. ${ }^{291,292}$ Dairy products have been found to reduce serum uric acid through the uricosuric effects of casein and lactalbumin, two proteins derived 

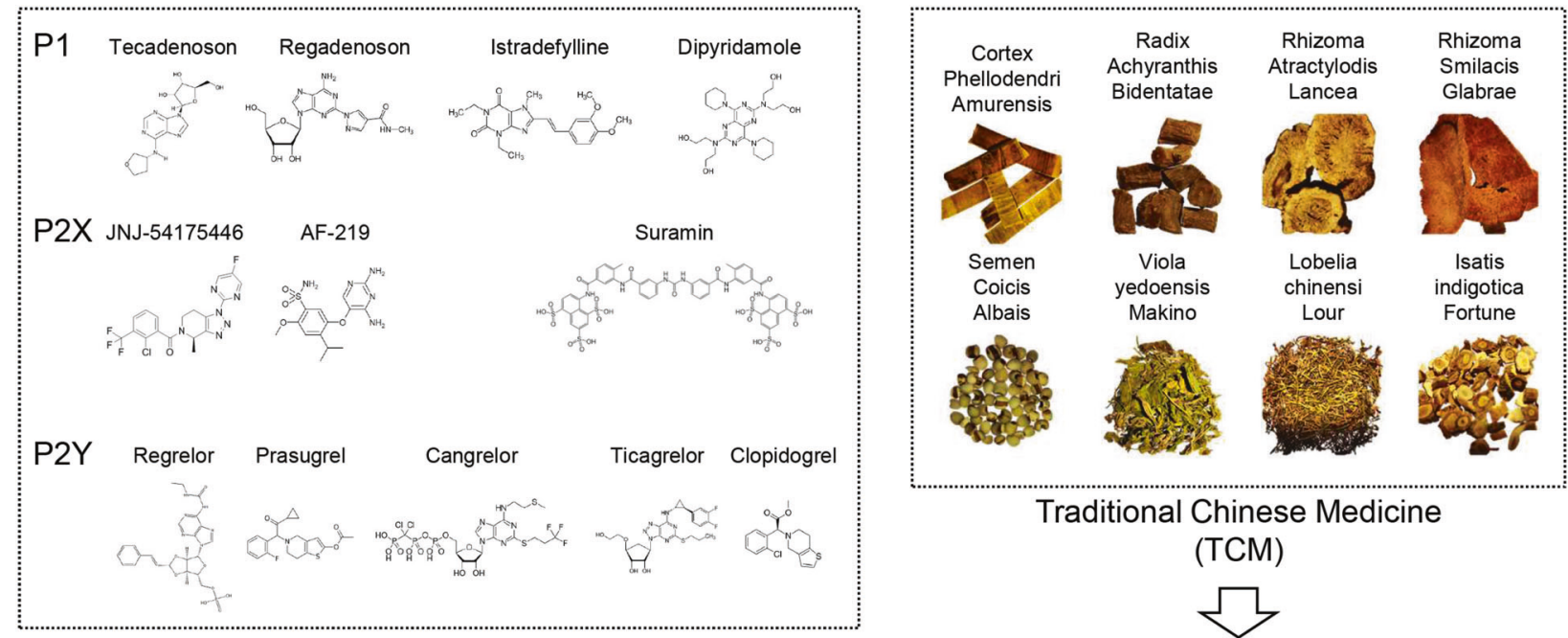

Purinergic Receptor

Agonist or Antagonist
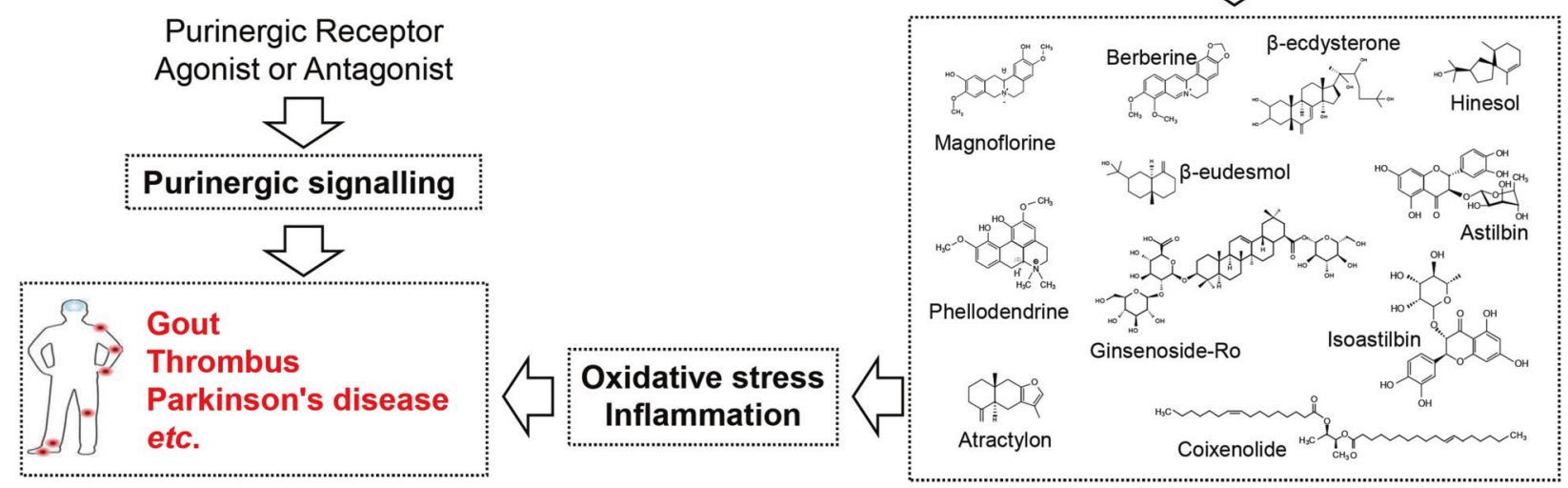

Active Ingredients

Fig. 7 Traditional Chinese medicine and evidence-based medicine with therapeutic potential for purine-related diseases. Several TCM have been found to show considerable effect in the treatment of gout, including Cortex Phellodendri Amurensis, Radix Achyranthis Bidentatae, Rhizoma Atractylodis Lancea, Rhizoma Smilacis Glabrae, Semen Coicis Albais, Viola yedoensis Makino, Lobelia chinensi Lour, Isatis indigotica Fortune and so on. These TCM share similarities in terms of their components, which usually contain antioxidant and anti-inflammatory materials such as berberine, phellodendrine and magnoflorine. Combinational use of TCM as a formula might improve therapeutic efficacy and minimised adverse effect. In addition, FDA-approved drugs including istradefylline, dipyridamole, suramin, clopidogrel, prasugrel, cangrelor, ticagrelor, etc. are also therapeutic options targeting purine metabolism or purinoceptors

from the milk. ${ }^{293,294}$ Coffee is a beneficial beverage, being associated with a lower risk of gout. ${ }^{295}$ Caffeine has been shown to competitively inhibit xanthine oxidase, the enzyme producing uric acid from hypoxanthine and xanthine. ${ }^{296}$ However, caffeine alone failed to reduce the risk of gout, suggesting that other components of coffee contribute to its beneficial effect. ${ }^{295}$

Dietary interventions are consistent with a theory of food homology according to traditional Chinese medicine (TCM), which describes that most foods hold therapeutic potential so that there is no absolute segregation between foods and drugs. In addition to physical methods such as acupuncture and cupping, TCM is mainly referred to herbal medicine that exhibits multi-targets effects. For instance, cortex phellodendri amurensis is one of the commonly used TCM for the treatment of gout. ${ }^{297}$ This effect might be attributed to its three components, berberine, phellodendrine and magnoflorine, all of which are capable of regulating inflammatory or antioxidant responses. ${ }^{298-300}$ Other TCM used for the treatment of gout include Radix Achyranthis Bidentatae, Rhizoma Atractylodis Lancea, Rhizoma Smilacis Glabrae, Semen Coicis Albais and Largehead Atractylodis Rhizome, with active ingredients such as $\beta$-ecdysterone, $\beta$-eudesmol, hinesol, atractylon and astilbin that exhibit anti-inflammatory, antioxidant or analgesic effects (Fig. 7). ${ }^{301}$ Importantly, in the clinic practice, different kinds of herbs are combined as complex formulae to minimise side effect and enhanced therapeutic outcome. For example, Erding granule (EDG) composed of Viola yedoensis Makino, Lobelia chinensi Lour, Isatis indigotica Fort and other components has been shown to reduce uric acid and suppress inflammation possibly via downregulating the expression of GLUT9 and URAT1 in a mouse model, suggesting this formula can be a potential agent for the treatment of hyperuricemia. ${ }^{302}$

It is worth mentioning that dietary and herbal interventions are useful for disease prevention or treatment at early stages. When diseases reach advanced stages, however, evidence-based medicine with specific drug target remains an optimal choice (Fig. 7). Hitherto, a number of drugs targeting purine metabolism or purinergic signalling have been developed. The US FDA database, contains several approved purinergic signalling targetrelated drugs, which include ADO injection [P1 receptor agonist used for the treatment of paroxysmal supraventricular tachycardia (PSVT) including that associated with accessory bypass tracts (Wolff-Parkinson-White syndrome)]; Cafcit (Caffeine citrate) injection ( $\mathrm{P} 1$ receptor antagonist for the treatment of apnoea of prematurity); Lexiscan (regadenoson) injection $\left(\mathrm{A} 2_{\mathrm{A}}\right.$ receptor agonist, used as a pharmacologic stress agent in radionuclide myocardial perfusion imaging, a test that detects and characterises coronary artery disease, in patients unable to undergo adequate exercise stress); Nourianz (Istradefylline) tablets ( $A 2_{A}$ 
receptor antagonist used as an add-on treatment to levodopa/ carbidopa in adult patients with Parkinson's disease experiencing "off" episodes); Brilinta (ticagrelor) tablets (P2Y 12 receptor antagonist, treatment for acute coronary syndrome, coronary artery disease, cardiovascular risk reduction, ischaemic stroke, and prophylaxis); Effient (Prasugrel) tablets ( $\mathrm{P}_{2} \mathrm{Y}_{12}$ receptor antagonist, oral antiplatelet agent for the treatment of patients with acute coronary syndrome who are managed with percutaneous coronary intervention including coronary stenting); Kengreal (Cangrelor) injection ( $\mathrm{P}_{2} \mathrm{Y}_{12}$ receptor antagonist, intravenous $\mathrm{P}_{2} \mathrm{Y}_{12}$ platelet inhibitor indicated for use in patients undergoing percutaneous coronary intervention to reduce the risk of periprocedural thrombotic events); Plavix (Clopidogrel bisulfate) tablets $\left(P_{2} Y_{12}\right.$ receptor antagonist, indicated for the reduction of atherothrombotic events such as recent myocardial infarction, recent stroke, or established peripheral arterial disease, and acute coronary syndrome); and dipyridamole tablets (inhibiting the uptake of adenosine into platelets, endothelial cells and erythrocytes in vitro and in vivo, used as an adjunct to coumarin anticoagulants in the prevention of postoperative thromboembolic complications of cardiac valve replacement). In addition, a variety of drugs have been studied and applied in clinic for the treatment of different diseases although they have not got approval from FDA. For example, Diquafosol (tradename Diquas) is a $\mathrm{P}_{2} \mathrm{Y}_{2}$ receptor agonist that has been approved for the treatment of dry eye disease in Japan in 2010 and it is available for dry eye treatment in Japan, South Korea, Thailand, Vietnam, and China. Topical instillation of $3 \%$ diquafosol ophthalmic solution increased lipid layer thickness within $60 \mathrm{~min}$ in normal human eyes regardless of age $\mathrm{e}^{303}$ and the recent real-world study showed that diquafosol $3.0 \%$ ophthalmic solution was well tolerated and effective in the long-term treatment (12 months) of dry eye. ${ }^{304}$ The Phase 3 trial for Denufosol (inhaled P2Y 2 agonists for the treatment of cystic fibrosis) is in the progress. The Phase 2 clinical trial of AZD9056 (P2X X $_{7}$ receptor antagonist) demonstrated statistically significant decrease in Crohn's Disease Activity Index from baseline in Crohn's patients receiving $200 \mathrm{mg}$ AZD9056 (UID for 4 weeks). Another $\mathrm{P}_{2} \mathrm{X}_{7}$ antagonist JNJ-54175446 is an orally bioavailable, central nervous system-penetrating; it is currently in Phase 2 clinical trial for the treatment of major depressive disorder (clinicaltrials.gov,NCT04116606). AF-219/gefapixant, a P2X 3 receptor antagonist has been through a randomised, double-blind, placebo-controlled phase 2 study for the treatment of the refractory chronic cough ${ }^{305}$ and a randomised, double-blind, controlled, parallel-group, phase $2 \mathrm{~b}$ trial for the treatment of refractory or unexplained chronic cough. ${ }^{306}$ All of these drugs should be strongly recommended as new therapies with widened clinic applications.

\section{CONCLUDING REMARKS}

Apart from serving as building blocks and energy source, purines regulate numerous cellular processes by initiating purinergic signalling. Purine metabolism regulated by purinosome determines the availability of purines, which act as endogenous ligands for a panel of purinergic receptors. Activation of purinergic receptors controls the production of various secondary messengers including $C A M P, D A G, I_{3}$ and $\mathrm{Ca}^{2+}$, thus leading to physiological consequences in normal conditions. In contrast, unhealthy diet, genetic variation or other pathological events disturbs purine metabolism, resulting neurodegeneration, gout, pain, inflammation and cancer. In addition to these disorders, purinergic signalling is related with many other diseases including cardiac, gastrointestinal, muscular, reproductive disorders and so on. Due to the extreme complexity of human body, we did not cover all these aspects, while we focused on representative examples.
As the novel drug target, purinergic signalling has a promising future in the development of new drugs or new indications due to current success in $A D O, A_{1}, A 2 a$, and $P 2 Y_{12}$ receptors. However, any of the four main purines, ATP, ADP, AMP, and ADO in the purinergic system, any of the three key enzymes, CD39, E-NPP, and $C D 73$, and any of the 19 purinergic receptors, four $P 1$ receptors $\left(A_{1}, A_{2 A}, A_{2 B}, A_{3}\right)$, seven $P 2 X\left(P 2 X_{1-7}\right)$, and eight $P 2 Y$ $\left(\mathrm{P} 2 \mathrm{Y}_{1,2,4,6,11-14}\right)$ need more attention in the future. In particular, the following therapies may come true in the near future: ATP for depression, AD; ADO for sleep disorders; CD73 for cancer or inflammation; $A 1$ receptor for pain and sleep disorders; $A 2_{A}$ receptor for $\mathrm{AD}$ and $\mathrm{PD} ; \mathrm{P}_{2} \mathrm{X}_{1}$ receptor for bladder disorder and hypertension; $\mathrm{P} 2 \mathrm{X}_{3}$ receptor for cough and hypertension; $\mathrm{P} 2 \mathrm{X}_{7}$ receptor for cytokine release syndrome, inflammatory disease, brain disorders, and cancer; $\mathrm{P} 2 \mathrm{Y}_{2}$ receptor for dry eye; $\mathrm{P}_{2} \mathrm{Y}_{12}$ receptor for pain and inflammation beyond current indications approved by FDA.

Though remarkable progress has been made in this field, several details remain to be elucidated for an in-depth understating towards purinergic signalling. For instance, how does each component of purinosome is well organised to form together and translocated to mitochondria? How to target a specific purinergic receptor without affecting other family members in the same subgroup? How to minimise potential side effects when targeting purinergic receptors due to multiple secondary messengers are simultaneously affected? These concerns need to be addressed before purine-based therapeutic strategies can be broadly applied for the treatment of relevant human diseases. ${ }^{307-309}$

We miss the creator of Purinergic Signalling ${ }^{310,311}$ Prof. Geoffrey Burnstock and we are very grateful for his great contributions to the discovery and characterisation of this novel molecular target for the development of promising drugs to treat human disease.

\section{ACKNOWLEDGEMENTS}

This article is dedicated to the memory of recently deceased Professor Geoffrey Burnstock. This work was supported by grants from National Key R\&D Programme of China (2019YFC1709101, 2020YFA0509400, 2020YFC2002705), the National Natural Science Foundation of China (81821002, 81790251, 81373735, 81972665), Guangdong Basic and Applied Basic Research Foundation (2019B030302012), the Project First-Class Disciplines Development of Chengdu University of Traditional Chinese Medicine (CZYHW1901), São Paulo Research Foundation (FAPESP 2018/07366-4), NSFC and RFBR (project number 21-54-53018, 82111530059), MDT programme of State Administration of Traditional Chinese Medicine, and Science and Technology Programme of Sichuan Province, China (2019YFH0108, 2021JDGD0037).

\section{ADDITIONAL INFORMATION}

Competing interests: The authors declare no competing interests.

\section{REFERENCES}

1. Drury, A. N. \& Szent-Gyorgyi, A. The physiological activity of adenine compounds with especial reference to their action upon the mammalian heart. $J$. Physiol. 68, 213-237 (1929).

2. Feldberg, W. \& Hebb, C. The stimulating action of phosphate compounds on the perfused superior cervical ganglion of the cat. J. Physiol. 107, 210-221 (1948).

3. Holton, $P$. The liberation of adenosine triphosphate on antidromic stimulation of sensory nerves. J. Physiol. 145, 494-504 (1959).

4. Burnstock, G. Purinergic nerves. Pharmacol. Rev. 24, 509-581 (1972).

5. Ralevic, V. \& Burnstock, G. Receptors for purines and pyrimidines. Pharmacol. Rev. 50, 413-492 (1998).

6. Neary, J. T., Shi, Y. F., Kang, Y. \& Tran, M. D. Opposing effects of P2X(7) and P2Y purine/pyrimidine-preferring receptors on proliferation of astrocytes induced by fibroblast growth factor-2: implications for CNS development, injury, and repair. J. Neurosci. Res. 86, 3096-3105 (2008).

7. Hechler, B. \& Gachet, C. Purinergic receptors in thrombosis and inflammation. Arterioscler. Thromb. Vasc. Biol. 35, 2307-2315 (2015).

8. Khakh, B. S. \& North, R. A. Neuromodulation by extracellular ATP and P2X receptors in the CNS. Neuron 76, 51-69 (2012). 
9. Pastor-Anglada, M. \& Perez-Torras, S. Who is who in adenosine transport. Front. Pharmacol. 9, 627 (2018)

10. Camici, M., Garcia-Gil, M., Pesi, R., Allegrini, S. \& Tozzi, M. G. Purine-metabolising enzymes and apoptosis in cancer. Cancers 11, 1354 (2019).

11. Silva, C. H., Silva, M., lulek, J. \& Thiemann, O. H. Structural complexes of human adenine phosphoribosyltransferase reveal novel features of the APRT catalytic mechanism. J. Biomol. Struct. Dyn. 25, 589-597 (2008).

12. Townsend, M. H., Robison, R. A. \& O'Neill, K. L. A review of HPRT and its emerging role in cancer. Med. Oncol. 35, 89 (2018).

13. Ipata, P. L. Origin, utilization, and recycling of nucleosides in the central nervous system. Adv. Physiol. Educ. 35, 342-346 (2011).

14. Rustum, Y. M., Takita, H. \& Gomez, G. The design of cancer chemotherapy: metabolic modulation and cellular de novo versus salvage metabolism. Antibiot. Chemother. (1971) 28, 86-93 (1980).

15. Pedley, A. M. \& Benkovic, S. J. A new view into the regulation of purine metabolism: the purinosome. Trends Biochem. Sci. 42, 141-154 (2017).

16. Welin, M. et al. Structural studies of tri-functional human GART. Nucleic Acids Res. 38, 7308-7319 (2010).

17. Skerlova, J. et al. Crystal structures of human PAICS reveal substrate and product binding of an emerging cancer target. J. Biol. Chem. 295, 11656-11668 (2020).

18. Bulock, K. G., Beardsley, G. P. \& Anderson, K. S. The kinetic mechanism of the human bifunctional enzyme ATIC (5-amino-4-imidazolecarboxamide ribonucleotide transformylase/inosine $5^{\prime}$-monophosphate cyclohydrolase). A surprising lack of substrate channeling. J. Biol. Chem. 277, 22168-22174 (2002).

19. Brayton, K. A. et al. Two genes for de novo purine nucleotide synthesis on human chromosome 4 are closely linked and divergently transcribed. J. Biol. Chem. 269, 5313-5321 (1994).

20. Schendel, F. J. \& Stubbe, J. Substrate specificity of formylglycinamidine synthetase. Biochemistry 25, 2256-2264 (1986).

21. Toth, E. A. \& Yeates, T. O. The structure of adenylosuccinate lyase, an enzyme with dual activity in the de novo purine biosynthetic pathway. Structure $\mathbf{8}$, 163-174 (2000).

22. Quinones, W. et al. Structure, properties, and function of glycosomes in Trypanosoma cruzi. Front. Cell. Infect. Microbiol. 10, 25 (2020).

23. An, S., Kumar, R., Sheets, E. D. \& Benkovic, S. J. Reversible compartmentalization of de novo purine biosynthetic complexes in living cells. Science 320, 103-106 (2008).

24. Fu, R. et al. Clinical severity in Lesch-Nyhan disease: the role of residual enzyme and compensatory pathways. Mol. Genet. Metab. 114, 55-61 (2015).

25. Zhao, H. et al. Quantitative analysis of purine nucleotides indicates that purinosomes increase de novo purine biosynthesis. J. Biol. Chem. 290, 6705-6713 (2015).

26. Deng, Y. et al. Mapping protein-protein proximity in the purinosome. J. Biol. Chem. 287, 36201-36207 (2012).

27. French, J. B. et al. Hsp70/Hsp90 chaperone machinery is involved in the assembly of the purinosome. Proc. Natl Acad. Sci. USA 110, 2528-2533 (2013).

28. French, J. B. et al. Spatial colocalization and functional link of purinosomes with mitochondria. Science 351, 733-737 (2016).

29. An, S., Deng, Y., Tomsho, J. W., Kyoung, M. \& Benkovic, S. J. Microtubule-assisted mechanism for functional metabolic macromolecular complex formation. Proc Natl Acad. Sci. USA 107, 12872-12876 (2010).

30. Chan, C. Y. et al. Microtubule-directed transport of purine metabolons drives their cytosolic transit to mitochondria. Proc. Natl Acad. Sci. USA 115, 13009-13014 (2018)

31. Jiang, X. \& Yeung, R. S. Regulation of microtubule-dependent protein transport by the TSC2/mammalian target of rapamycin pathway. Cancer Res. 66, 5258-5269 (2006).

32. An, S., Kyoung, M., Allen, J. J., Shokat, K. M. \& Benkovic, S. J. Dynamic regulation of a metabolic multi-enzyme complex by protein kinase CK2. J. Biol. Chem. 285, 11093-11099 (2010)

33. Schmitt, D. L., Sundaram, A., Jeon, M., Luu, B. T. \& An, S. Spatial alterations of De Novo purine biosynthetic enzymes by Akt-independent PDK1 signaling pathways. PLoS ONE 13, e0195989 (2018)

34. Fang, Y., French, J., Zhao, H. \& Benkovic, S. G-protein-coupled receptor regulation of de novo purine biosynthesis: a novel druggable mechanism. Biotechnol. Genet. Eng. Rev. 29, 31-48 (2013).

35. Dalbeth, N. et al. Gout. Nat. Rev. Dis. Prim. 5, 69 (2019).

36. Liu, R. et al. Prevalence of hyperuricemia and gout in mainland China from 2000 to 2014: a systematic review and meta-analysis. Biomed. Res. Int. 2015, 762820 (2015).

37. Richette, P. \& Bardin, T. Gout. Lancet 375, 318-328 (2010).

38. Loguercio, C. et al. Intravenous load of fructose and fructose 1,6-diphosphate: effects on uricemia in patients with nonalcoholic liver disease. Am. J. Gastroenterol. 91, 559-564 (1996).
39. Gaffo, A. L. et al. Serum urate and its relationship with alcoholic beverage intake in men and women: findings from the Coronary Artery Risk Development in Young Adults (CARDIA) cohort. Ann. Rheum. Dis. 69, 1965-1970 (2010).

40. Wang, M. et al. Elevated fructose and uric acid via aldose reductase contribute to experimental and human alcoholic liver disease. Hepatology 72, 1617-1637 (2020).

41. Choi, H. K., Willett, W. \& Curhan, G. Fructose-rich beverages and risk of gout in women. JAMA 304, 2270-2278 (2010).

42. Faller, J. \& Fox, I. H. Ethanol-induced hyperuricemia: evidence for increased urate production by activation of adenine nucleotide turnover. N. Engl. J. Med. 307, 1598-1602 (1982).

43. Wu, X. W., Lee, C. C., Muzny, D. M. \& Caskey, C. T. Urate oxidase: primary structure and evolutionary implications. Proc. Natl Acad. Sci. USA 86, 9412-9416 (1989).

44. Ames, B. N., Cathcart, R., Schwiers, E. \& Hochstein, P. Uric acid provides an antioxidant defense in humans against oxidant- and radical-caused aging and cancer: a hypothesis. Proc. Natl Acad. Sci. USA 78, 6858-6862 (1981).

45. Sundy, J. S. et al. Efficacy and tolerability of pegloticase for the treatment of chronic gout in patients refractory to conventional treatment: two randomized controlled trials. JAMA 306, 711-720 (2011).

46. Maiuolo, J., Oppedisano, F., Gratteri, S., Muscoli, C. \& Mollace, V. Regulation of uric acid metabolism and excretion. Int. J. Cardiol. 213, 8-14 (2016).

47. Nakayama, A. et al. GWAS of clinically defined gout and subtypes identifies multiple susceptibility loci that include urate transporter genes. Ann. Rheum. Dis. 76, 869-877 (2017).

48. Enomoto, A. et al. Molecular identification of a renal urate anion exchanger that regulates blood urate levels. Nature 417, 447-452 (2002).

49. Matsuo, $\mathrm{H}$. et al. Mutations in glucose transporter 9 gene SLC2A9 cause renal hypouricemia. Am. J. Hum. Genet. 83, 744-751 (2008).

50. Matsuo, $\mathrm{H}$. et al. ABCG2 dysfunction causes hyperuricemia due to both renal urate underexcretion and renal urate overload. Sci. Rep. 4, 3755 (2014).

51. Chiba, T. et al. NPT1/SLC17A1 is a renal urate exporter in humans and its common gain-of-function variant decreases the risk of renal underexcretion gout. Arthritis Rheumatol. 67, 281-287 (2015).

52. Matsuo, $\mathrm{H}$. et al. Hyperuricemia in acute gastroenteritis is caused by decreased urate excretion via ABCG2. Sci. Rep. 6, 31003 (2016).

53. Sakiyama, M. et al. The effects of URAT1/SLC22A12 nonfunctional variants, $R 90 \mathrm{H}$ and $\mathrm{W} 258 \mathrm{X}$, on serum uric acid levels and gout/hyperuricemia progression. Sci. Rep. 6, 20148 (2016).

54. Ruiz, A., Gautschi, I., Schild, L. \& Bonny, O. Human mutations in SLC2A9 (Glut9) affect transport capacity for urate. Front. Physiol. 9, 476 (2018).

55. Woodward, O. M. et al. Identification of a urate transporter, ABCG2, with a common functional polymorphism causing gout. Proc. Natl Acad. Sci. USA 106, 10338-10342 (2009).

56. Tin, A. et al. Target genes, variants, tissues and transcriptional pathways influencing human serum urate levels. Nat. Genet. 51, 1459-1474 (2019).

57. Loeb, J. N. The influence of temperature on the solubility of monosodium urate. Arthritis Rheum. 15, 189-192 (1972).

58. Mitroulis, I., Kambas, K. \& Ritis, K. Neutrophils, IL-1beta, and gout: is there a link? Semin. Immunopathol. 35, 501-512 (2013).

59. Hari, A. et al. Activation of NLRP3 inflammasome by crystalline structures via cell surface contact. Sci. Rep. 4, 7281 (2014).

60. Popa-Nita, O. \& Naccache, P. H. Crystal-induced neutrophil activation. Immunol. Cell Biol. 88, 32-40 (2010).

61. Chen, Y. H. et al. Spontaneous resolution of acute gouty arthritis is associated with rapid induction of the anti-inflammatory factors TGFbeta1, IL-10 and soluble TNF receptors and the intracellular cytokine negative regulators $\mathrm{CIS}$ and SOCS3. Ann. Rheum. Dis. 70, 1655-1663 (2011).

62. Zeng, M. et al. IL-37 inhibits the production of pro-inflammatory cytokines in MSU crystal-induced inflammatory response. Clin. Rheumatol. 35, 2251-2258 (2016).

63. Schauer, C. et al. Aggregated neutrophil extracellular traps limit inflammation by degrading cytokines and chemokines. Nat. Med. 20, 511-517 (2014).

64. Apel, F., Zychlinsky, A. \& Kenny, E. F. The role of neutrophil extracellular traps in rheumatic diseases. Nat. Rev. Rheumatol. 14, 467-475 (2018).

65. Ragab, G., Elshahaly, M. \& Bardin, T. Gout: An old disease in new perspective-a review. J. Adv. Res. 8, 495-511 (2017).

66. Towiwat, P. et al. Urate crystal deposition and bone erosion in gout: 'inside-out' or 'outside-in'? A dual-energy computed tomography study. Arthritis Res. Ther. 18, 208 (2016).

67. Chhana, A. et al. Monosodium urate monohydrate crystals inhibit osteoblast viability and function: implications for development of bone erosion in gout. Ann. Rheum. Dis. 70, 1684-1691 (2011).

68. Dalbeth, N. et al. Enhanced osteoclastogenesis in patients with tophaceous gout: urate crystals promote osteoclast development through interactions with stromal cells. Arthritis Rheum. 58, 1854-1865 (2008). 
69. Kok, V. C. et al. Gout as a risk factor for osteoporosis: epidemiologic evidence from a population-based longitudinal study involving 108,060 individuals. Osteoporos. Int. 29, 973-985 (2018).

70. Richette, P. et al. 2016 updated EULAR evidence-based recommendations for the management of gout. Ann. Rheum. Dis. 76, 29-42 (2017).

71. Pacher, P., Nivorozhkin, A. \& Szabo, C. Therapeutic effects of xanthine oxidase inhibitors: renaissance half a century after the discovery of allopurinol. Pharmacol. Rev. 58, 87-114 (2006).

72. Cameron, J. S., Moro, F. \& Simmonds, H. A. Gout, uric acid and purine metabolism in paediatric nephrology. Pediatr. Nephrol. 7, 105-118 (1993).

73. Stamp, L. K. et al. A randomised controlled trial of the efficacy and safety of allopurinol dose escalation to achieve target serum urate in people with gout. Ann. Rheum. Dis. 76, 1522-1528 (2017).

74. Hung, S. I. et al. HLA-B*5801 allele as a genetic marker for severe cutaneous adverse reactions caused by allopurinol. Proc. Natl Acad. Sci. USA 102, 4134-4139 (2005).

75. Esposito, A. J. et al. Acute kidney injury in allopurinol-induced DRESS syndrome: a case report of concurrent tubulointerstitial nephritis and kidney-limited necrotizing vasculitis. Clin. Nephrol. 87, 316-319 (2017).

76. Day, R. O. et al. Clinical pharmacokinetics and pharmacodynamics of allopurinol and oxypurinol. Clin. Pharmacokinet. 46, 623-644 (2007).

77. Vargas-Santos, A. B., Peloquin, C. E., Zhang, Y. \& Neogi, T. Association of Chronic Kidney Disease With Allopurinol Use in Gout Treatment. JAMA Intern. Med. 178, 1526-1533 (2018).

78. Zhang, X., Wan, D., Yang, G., Peng, Q. \& Wang, X. Febuxostat is superior to allopurinol in delaying the progression of renal impairment in patients with chronic kidney disease and hyperuricemia. Int. Urol. Nephrol. 51, 2273-2283 (2019).

79. Bohm, M., Vuppalanchi, R. \& Chalasani, N. \& Drug-Induced Liver Injury, N. Febuxostat-induced acute liver injury. Hepatology 63, 1047-1049 (2016).

80. White, W. B. et al. Cardiovascular safety of febuxostat or allopurinol in patients with gout. N. Engl. J. Med. 378, 1200-1210 (2018).

81. Dalbeth, N., Merriman, T. R. \& Stamp, L. K. Gout. Lancet 388, 2039-2052 (2016).

82. Burnstock, G. Pathophysiology and therapeutic potential of purinergic signaling. Pharmacol. Rev. 58, 58-86 (2006).

83. Mustafa, S. J., Morrison, R. R., Teng, B. \& Pelleg, A. Adenosine receptors and the heart: role in regulation of coronary blood flow and cardiac electrophysiology. Handb. Exp. Pharmacol. 6, 161-188 (2009).

84. Fredholm, B. B., AP, I. J., Jacobson, K. A., Klotz, K. N. \& Linden, J. International Union of Pharmacology. XXV. Nomenclature and classification of adenosine receptors. Pharmacol. Rev. 53, 527-552 (2001).

85. Sachdeva, S. \& Gupta, M. Adenosine and its receptors as therapeutic targets: an overview. Saudi. Pharm. J. 21, 245-253 (2013).

86. Cieslak, M., Komoszynski, M., Wojtczak, A. \& Adenosine, A. Adenosine A(2A) receptors in Parkinson's disease treatment. Plurinergic Signal. 4, 305-312 (2008).

87. Poulsen, S. A. \& Quinn, R. J. Adenosine receptors: new opportunities for future drugs. Bioorg. Med. Chem. 6, 619-641 (1998).

88. Sassi, Y. et al. Cardiac myocyte-secreted CAMP exerts paracrine action via adenosine receptor activation. J. Clin. Investig. 124, 5385-5397 (2014).

89. Biber, K., Klotz, K. N., Berger, M., Gebicke-Harter, P. J. \& van Calker, D. Adenosine A1 receptor-mediated activation of phospholipase $C$ in cultured astrocytes depends on the level of receptor expression. J. Neurosci. 17, 4956-4964 (1997).

90. Robinson, A. J. \& Dickenson, J. M. Regulation of p42/p44 MAPK and p38 MAPK by the adenosine $A(1)$ receptor in DDT(1)MF-2 cells. Eur. J. Pharmacol. 413, 151-161 (2001).

91. Brugarolas, M. et al. G-protein-coupled receptor heteromers as key players in the molecular architecture of the central nervous system. CNS Neurosci. Ther. 20, 703-709 (2014).

92. Navarro, G. et al. Quaternary structure of a G-protein-coupled receptor heterotetramer in complex with Gi and Gs. BMC Biol. 14, 26 (2016).

93. Borea, P. A., Gessi, S., Merighi, S., Vincenzi, F. \& Varani, K. Pharmacology of adenosine receptors: the state of the art. Physiol. Rev. 98, 1591-1625 (2018).

94. Reiss, A. B. et al. Adenosine and the cardiovascular system. Am. J. Cardiovasc. Drugs 19, 449-464 (2019).

95. Burnstock, G. Purine and purinergic receptors. Brain Neurosci. Adv. 2, 2398212818817494 (2018).

96. Lustig, K. D., Shiau, A. K., Brake, A. J. \& Julius, D. Expression cloning of an ATP receptor from mouse neuroblastoma cells. Proc. Natl Acad. Sci. USA 90, 5113-5117 (1993).

97. Webb, T. E. et al. Cloning and functional expression of a brain G-protein-coupled ATP receptor. FEBS Lett. 324, 219-225 (1993).

98. Brake, A. J., Wagenbach, M. J. \& Julius, D. New structural motif for ligand-gated ion channels defined by an ionotropic ATP receptor. Nature 371, 519-523 (1994)
99. Valera, S. et al. A new class of ligand-gated ion channel defined by P2x receptor for extracellular ATP. Nature 371, 516-519 (1994).

100. Di Virgilio, F., Sarti, A. C., Falzoni, S., De Marchi, E. \& Adinolfi, E. Extracellular ATP and $\mathrm{P} 2$ purinergic signalling in the tumour microenvironment. Nat. Rev. Cancer 18, 601-618 (2018).

101. Fagura, M. S. et al. P2Y1-receptors in human platelets which are pharmacologically distinct from P2Y(ADP)-receptors. Br. J. Pharmacol. 124, 157-164 (1998).

102. Nicholas, R. A., Watt, W. C., Lazarowski, E. R., Li, Q. \& Harden, K. Uridine nucleotide selectivity of three phospholipase C-activating P2 receptors: identification of a UDP-selective, a UTP-selective, and an ATP- and UTP-specific receptor. Mol. Pharmacol. 50, 224-229 (1996).

103. Abbracchio, M. P. et al. International Union of Pharmacology LVIII: update on the P2Y G protein-coupled nucleotide receptors: from molecular mechanisms and pathophysiology to therapy. Pharmacol. Rev. 58, 281-341 (2006).

104. Simon, J. et al. Characterization and channel coupling of the P2Y(12) nucleotide receptor of brain capillary endothelial cells. J. Biol. Chem. 277, 31390-31400 (2002).

105. Communi, D., Motte, S., Boeynaems, J. M. \& Pirotton, S. Pharmacological characterization of the human P2Y4 receptor. Eur. J. Pharmacol. 317, 383-389 (1996).

106. Bogdanov, Y. D., Wildman, S. S., Clements, M. P., King, B. F. \& Burnstock, G. Molecular cloning and characterization of rat P2Y4 nucleotide receptor. Br. J. Pharmacol. 124, 428-430 (1998).

107. Jiang, R., Taly, A. \& Grutter, T. Moving through the gate in ATP-activated P2X receptors. Trends Biochem. Sci. 38, 20-29 (2013).

108. Kasuya, G. et al. Structural insights into the nucleotide base specificity of P2X receptors. Sci. Rep. 7, 45208 (2017).

109. Evans, R. J. et al. Pharmacological characterization of heterologously expressed ATP-gated cation channels (P2x purinoceptors). Mol. Pharmacol. 48, 178-183 (1995).

110. Yan, Z. et al. Experimental characterization and mathematical modeling of $P 2 X 7$ receptor channel gating. J. Neurosci. 30, 14213-14224 (2010).

111. Schmid, R. \& Evans, R. J. ATP-gated P2X receptor channels: molecular insights into functional roles. Annu. Rev. Physiol. 81, 43-62 (2019).

112. Barrera, N. P., Ormond, S. J., Henderson, R. M., Murrell-Lagnado, R. D. \& Edwardson, J. M. Atomic force microscopy imaging demonstrates that P2X2 receptors are trimers but that $\mathrm{P} 2 \mathrm{X} 6$ receptor subunits do not oligomerize. J. Biol. Chem. 280, 10759-10765 (2005).

113. Coddou, C., Yan, Z., Obsil, T., Huidobro-Toro, J. P. \& Stojilkovic, S. S. Activation and regulation of purinergic P2X receptor channels. Pharmacol. Rev. 63, 641-683 (2011).

114. Aschrafi, A., Sadtler, S., Niculescu, C., Rettinger, J. \& Schmalzing, G. Trimeric architecture of homomeric $\mathrm{P} 2 \mathrm{X} 2$ and heteromeric $\mathrm{P} 2 \mathrm{X} 1+2$ receptor subtypes. J. Mol. Biol. 342, 333-343 (2004).

115. Jiang, L. H. et al. Subunit arrangement in P2X receptors. J. Neurosci. 23, 8903-8910 (2003).

116. Antonio, L. S., Stewart, A. P., Varanda, W. A. \& Edwardson, J. M. Identification of $\mathrm{P} 2 \mathrm{X} 2 / \mathrm{P} 2 \mathrm{X} 4 / \mathrm{P} 2 \mathrm{X} 6$ heterotrimeric receptors using atomic force microscopy (AFM) imaging. FEBS Lett. 588, 2125-2128 (2014).

117. Baqi, Y. \& Muller, C. E. Antithrombotic P2Y12 receptor antagonists: recent developments in drug discovery. Drug Discov. Today 24, 325-333 (2019).

118. Abdulqawi, R. et al. $\mathrm{P} 2 \mathrm{X} 3$ receptor antagonist (AF-219) in refractory chronic cough: a randomised, double-blind, placebo-controlled phase 2 study. Lancet 385, 1198-1205 (2015).

119. Meibom, D. et al. Neladenoson bialanate hydrochloride: a prodrug of a partial adenosine A1 receptor agonist for the chronic treatment of heart diseases. ChemMedChem 12, 728-737 (2017)

120. Hanahan, D. \& Weinberg, R. A. Hallmarks of cancer: the next generation. Cell 144, 646-674 (2011)

121. Gilbert, S. M. et al. ATP in the tumour microenvironment drives expression of nfP2X7, a key mediator of cancer cell survival. Oncogene 38, 194-208 (2019).

122. Burnstock, G. \& Di Virgilio, F. Purinergic signalling and cancer. Purinergic Signal. 9, 491-540 (2013).

123. Lelievre, V., Muller, J. M. \& Falcon, J. Adenosine modulates cell proliferation in human colonic adenocarcinoma. I. Possible involvement of adenosine A1 receptor subtypes in HT29 cells. Eur. J. Pharmacol. 341, 289-297 (1998).

124. Farrell, A. W. et al. P2X7 receptor activation induces cell death and CD23 shedding in human RPMI 8226 multiple myeloma cells. Biochim. Biophys. Acta 1800, 1173-1182 (2010).

125. Vijayan, D., Young, A., Teng, M. W. L. \& Smyth, M. J. Targeting immunosuppressive adenosine in cancer. Nat. Rev. Cancer 17, 709-724 (2017).

126. Allard, B., Allard, D., Buisseret, L. \& Stagg, J. The adenosine pathway in immunooncology. Nat. Rev. Clin. Oncol. 17, 611-629 (2020)

127. Pellegatti, P. et al. Increased level of extracellular ATP at tumor sites: in vivo imaging with plasma membrane luciferase. PLoS ONE 3, e2599 (2008). 
128. Kamata-Sakurai, M. et al. Antibody to CD137 activated by extracellular adenosine triphosphate is tumor selective and broadly effective in vivo without systemic immune activation. Cancer Discov. 11, 328 (2020).

129. Abbracchio, M. P., Burnstock, G., Verkhratsky, A. \& Zimmermann, H. Purinergic signalling in the nervous system: an overview. Trends Neurosci. 32, 19-29 (2009).

130. Sawada, K. et al. Identification of a vesicular nucleotide transporter. Proc. Natl Acad. Sci. USA 105, 5683-5686 (2008).

131. Bal-Price, A., Moneer, Z. \& Brown, G. C. Nitric oxide induces rapid, calciumdependent release of vesicular glutamate and ATP from cultured rat astrocytes. Glia 40, 312-323 (2002).

132. Vessey, K. A., Ho, T., Jobling, A. I., Wang, A. Y. \& Fletcher, E. L. Fluorescent labeling and quantification of vesicular ATP release using live cell imaging. Methods Mol. Biol. 2041, 209-221 (2020)

133. Xiong, Y. et al. Stretch-induced Ca2+ independent ATP release in hippocampal astrocytes. J. Physiol. 596, 1931-1947 (2018).

134. Pankratov, Y., Lalo, U., Verkhratsky, A. \& North, R. A. Vesicular release of ATP at central synapses. Pflug. Arch. 452, 589-597 (2006).

135. Potter, P. \& White, T. D. Release of adenosine $5^{\prime}$-triphosphate from synaptosomes from different regions of rat brain. Neuroscience 5, 1351-1356 (1980).

136. Pankratov, Y., Lalo, U., Verkhratsky, A. \& North, R. A. Quantal release of ATP in mouse cortex. J. Gen. Physiol. 129, 257-265 (2007).

137. Kaan, T. K. et al. Endogenous purinergic control of bladder activity via presynaptic $\mathrm{P} 2 \mathrm{X} 3$ and $\mathrm{P} 2 \mathrm{X} 2 / 3$ receptors in the spinal cord. J. Neurosci. 30 4503-4507 (2010)

138. Burnstock, G. P2X receptors in sensory neurones. Br. J. Anaesthesiol. 84, 476-488 (2000).

139. Pougnet, J. T. et al. ATP P2X receptors downregulate AMPA receptor trafficking and postsynaptic efficacy in hippocampal neurons. Neuron 83, 417-430 (2014).

140. Tai, Y. H., Cheng, P. Y., Tsai, R. Y., Chen, Y. F. \& Wong, C. S. Purinergic P2X receptor regulates $\mathrm{N}$-methyl-D-aspartate receptor expression and synaptic excitatory amino acid concentration in morphine-tolerant rats. Anesthesiology 113, 1163-1175 (2010)

141. Rodrigues, R. J., Almeida, T., Richardson, P. J., Oliveira, C. R. \& Cunha, R. A. Dual presynaptic control by ATP of glutamate release via facilitatory P2X1, P2X2/3, and $\mathrm{P} 2 \mathrm{X} 3$ and inhibitory $\mathrm{P} 2 \mathrm{Y} 1, \mathrm{P} 2 \mathrm{Y} 2$, and/or $\mathrm{P} 2 \mathrm{Y} 4$ receptors in the rat hippocampus. J. Neurosci. 25, 6286-6295 (2005).

142. Fredholm, B. B., Chen, J. F., Cunha, R. A., Svenningsson, P. \& Vaugeois, J. M. Adenosine and brain function. Int. Rev. Neurobiol. 63, 191-270 (2005).

143. Klishin, A., Lozovaya, N. \& Krishtal, O. A1 adenosine receptors differentially regulate the $\mathrm{N}$-methyl-D-aspartate and non-N-methyl-D-aspartate receptormediated components of hippocampal excitatory postsynaptic current in a Ca2+/Mg(2+)-dependent manner. Neuroscience 65, 947-953 (1995).

144. Klishin, A., Tsintsadze, T., Lozovaya, N. \& Krishtal, O. Latent N-methyl-D-aspartate receptors in the recurrent excitatory pathway between hippocampal CA1 pyramidal neurons: Ca2+-dependent activation by blocking A1 adenosine receptors. Proc. Natl Acad. Sci. USA 92, 12431-12435 (1995).

145. Barrie, A. P. \& Nicholls, D. G. Adenosine A1 receptor inhibition of glutamate exocytosis and protein kinase C-mediated decoupling. J. Neurochem. 60, 1081-1086 (1993).

146. Okada, M., Fukuyama, K., Shiroyama, T. \& Ueda, Y. Carbamazepine attenuates astroglial L-glutamate release induced by pro-inflammatory cytokines via chronically activation of adenosine A2A receptor. Int. J. Mol. Sci. 20, 3727 (2019).

147. Guntz, E. et al. Expression of adenosine A 2 A receptors in the rat lumbar spinal cord and implications in the modulation of $\mathrm{N}$-methyl-D-aspartate receptor currents. Anesth. Analg. 106, 1882-1889 (2008).

148. Burnstock, G. Introduction to purinergic signalling in the brain. Adv. Exp. Med. Biol. 1202, 1-12 (2020).

149. Oliveira, A., Illes, P. \& Ulrich, H. Purinergic receptors in embryonic and adult neurogenesis. Neuropharmacology 104, 272-281 (2016).

150. Cheung, K. K. \& Burnstock, G. Localization of $P 2 X 3$ receptors and coexpression with $\mathrm{P} 2 \mathrm{X} 2$ receptors during rat embryonic neurogenesis. J. Comp. Neurol. 443, 368-382 (2002)

151. Mcllwrath, S. L., Davis, B. M. \& Bielefeldt, K. Deletion of P2X3 receptors blunts gastro-oesophageal sensation in mice. Neurogastroenterol. Motil. 21, 890-e866 (2009).

152. Cheung, K. K., Ryten, M. \& Burnstock, G. Abundant and dynamic expression of G protein-coupled $\mathrm{P} 2 \mathrm{Y}$ receptors in mammalian development. Dev. Dyn. 228, 254-266 (2003)

153. Guo, W. et al. Developmental expression of P2X5 receptors in the mouse prenatal central and peripheral nervous systems. Purinergic Signal. 9, 239-248 (2013).

154. Arthur, D. B., Akassoglou, K. \& Insel, P. A. P2Y2 receptor activates nerve growth factor/TrkA signaling to enhance neuronal differentiation. Proc. Natl Acad. Sci. USA 102, 19138-19143 (2005).
155. Silva, C. G. et al. Adenosine receptor antagonists including caffeine alter fetal brain development in mice. Sci. Transl. Med. 5, 197ra104 (2013).

156. Tang, Y. \& Illes, P. Regulation of adult neural progenitor cell functions by purinergic signaling. Glia 65, 213-230 (2017).

157. Jin, K. et al. Neurogenesis in dentate subgranular zone and rostral subventricular zone after focal cerebral ischemia in the rat. Proc. Natl Acad. Sci. USA 98, 4710-4715 (2001)

158. Collo, G. et al. Tissue distribution of the P2X7 receptor. Neuropharmacology 36, 1277-1283 (1997)

159. Glaser, T. et al. Modulation of mouse embryonic stem cell proliferation and neural differentiation by the P2X7 receptor. PLOS ONE 9, e96281 (2014).

160. Leeson, H. C. et al. P2X7 receptor signaling during adult hippocampal neurogenesis. Neural Regen. Res. 14, 1684-1694 (2019).

161. Scemes, E., Duval, N. \& Meda, P. Reduced expression of P2Y1 receptors in connexin43-null mice alters calcium signaling and migration of neural progenitor cells. J. Neurosci. 23, 11444-11452 (2003).

162. Shinozaki, Y. et al. Transformation of astrocytes to a neuroprotective phenotype by microglia via P2Y1 receptor downregulation. Cell Rep. 19, 1151-1164 (2017).

163. Solini, A. et al. Multiple $\mathrm{P} 2 \mathrm{X}$ receptors are involved in the modulation of apoptosis in human mesangial cells: evidence for a role of P2X4. Am. J. Physiol. Ren. Physiol. 292, F1537-F1547 (2007).

164. Ye, X. et al. Purinergic $2 X 7$ receptor/NLRP3 pathway triggers neuronal apoptosis after ischemic stroke in the mouse. Exp. Neurol. 292, 46-55 (2017).

165. Arthur, D. B., Georgi, S., Akassoglou, K. \& Insel, P. A. Inhibition of apoptosis by P2Y2 receptor activation: novel pathways for neuronal survival. J. Neurosci. 26 3798-3804 (2006)

166. $\mathrm{Xu}, \mathrm{Y}$. et al. P2Y6 receptor-mediated microglial phagocytosis in radiationinduced brain injury. Mol. Neurobiol. 53, 3552-3564 (2016).

167. Mattson, M. P. \& Chan, S. L. Calcium orchestrates apoptosis. Nat. Cell Biol. 5, 1041-1043 (2003)

168. Burnstock, G. Purinergic signalling and neurological diseases: an update. CNS Neurol. Disord. Drug Targets 16, 257-265 (2017).

169. Cheffer, A. et al. Purinergic system in psychiatric diseases. Mol. Psychiatry 23, 94-106 (2018).

170. Glaser, T. et al. ATP and spontaneous calcium oscillations control neural stem cell fate determination in Huntington's disease: a novel approach for cell clock research. Mol. Psychiatry 20, 717 (2020).

171. Oliveira-Giacomelli, A. et al. Purinergic receptors in neurological diseases with motor symptoms: targets for therapy. Front. Pharmacol. 9, 325 (2018).

172. Kalaria, R. N., Sromek, S., Wilcox, B. J. \& Unnerstall, J. R. Hippocampal adenosine A1 receptors are decreased in Alzheimer's disease. Neurosci. Lett. 118, 257-260 (1990).

173. Gussago, C. et al. Different adenosine A2A receptor expression in peripheral cells from elderly patients with vascular dementia and Alzheimer's disease. $J$. Alzheimers Dis. 40, 45-49 (2014).

174. Angulo, E. et al. A1 adenosine receptors accumulate in neurodegenerative structures in Alzheimer disease and mediate both amyloid precursor protein processing and tau phosphorylation and translocation. Brain Pathol. 13, 440-451 (2003)

175. Laurent, C. et al. A2A adenosine receptor deletion is protective in a mouse model of Tauopathy. Mol. Psychiatry 21, 97-107 (2016).

176. Li, P. et al. Optogenetic activation of intracellular adenosine A2A receptor signaling in the hippocampus is sufficient to trigger CREB phosphorylation and impair memory. Mol. Psychiatry 20, 1339-1349 (2015).

177. Hussain, A., Tabrez, E. S., Mavrych, V., Bolgova, O. \& Peela, J. R. Caffeine: a potential protective agent against cognitive decline in Alzheimer's disease. Crit. Rev. Eukaryot. Gene Expr. 28, 67-72 (2018).

178. Kolahdouzan, M. \& Hamadeh, M. J. The neuroprotective effects of caffeine in neurodegenerative diseases. CNS Neurosci. Ther. 23, 272-290 (2017).

179. Chen, X., Ghribi, O. \& Geiger, J. D. Caffeine protects against disruptions of the blood-brain barrier in animal models of Alzheimer's and Parkinson's diseases. J. Alzheimers Dis. 20, S127-S141 (2010)

180. Thomas, S. C., Alhasawi, A., Appanna, V. P., Auger, C. \& Appanna, V. D. Brain metabolism and Alzheimer's disease: the prospect of a metabolite-based therapy. J. Nutr. Health Aging 19, 58-63 (2015).

181. Ryu, J. K. \& McLarnon, J. G. Block of purinergic P2X(7) receptor is neuroprotective in an animal model of Alzheimer's disease. Neuroreport 19, 1715-1719 (2008).

182. Takenouchi, T. et al. $\mathrm{P} 2 \mathrm{X} 7$ receptor signaling pathway as a therapeutic target for neurodegenerative diseases. Arch. Immunol. Ther. Exp. 58, 91-96 (2010).

183. McLarnon, J. G., Ryu, J. K., Walker, D. G. \& Choi, H. B. Upregulated expression of purinergic $\mathrm{P} 2 \mathrm{X}(7)$ receptor in Alzheimer disease and amyloid-beta peptidetreated microglia and in peptide-injected rat hippocampus. J. Neuropathol. Exp. Neurol. 65, 1090-1097 (2006). 
184. Parvathenani, L. K. et al. P2X7 mediates superoxide production in primary microglia and is up-regulated in a transgenic mouse model of Alzheimer's disease. J. Biol. Chem. 278, 13309-13317 (2003).

185. Diaz-Hernandez, J. I. et al. In vivo P2X7 inhibition reduces amyloid plaques in Alzheimer's disease through GSK3beta and secretases. Neurobiol. Aging 33, 1816-1828 (2012).

186. Delarasse, C., Auger, R., Gonnord, P., Fontaine, B. \& Kanellopoulos, J. M. The purinergic receptor $\mathrm{P} 2 \mathrm{X} 7$ triggers alpha-secretase-dependent processing of the amyloid precursor protein. J. Biol. Chem. 286, 2596-2606 (2011).

187. Park, H., Suh, B. S. \& Lee, K. Relationship between daily coffee intake and suicidal ideation. J. Affect. Disord. 256, 468-472 (2019).

188. Grosso, G., Micek, A., Castellano, S., Pajak, A. \& Galvano, F. Coffee, tea, caffeine and risk of depression: a systematic review and dose-response meta-analysis of observational studies. Mol. Nutr. Food Res. 60, 223-234 (2016).

189. Padilla, K. M. et al. Behavioral changes induced through adenosine A2A receptor ligands in a rat depression model induced by olfactory bulbectomy. Brain Behav. 8, e00952 (2018).

190. Coelho, J. E. et al. Overexpression of adenosine A2A receptors in rats: effects on depression, locomotion, and anxiety. Front. Psychiatry 5, 67 (2014).

191. Serchov, T. et al. Increased signaling via adenosine A1 receptors, sleep deprivation, imipramine, and ketamine inhibit depressive-like behavior via induction of Homer1a. Neuron 87, 549-562 (2015).

192. Hines, D. J., Schmitt, L. I., Hines, R. M., Moss, S. J. \& Haydon, P. G. Antidepressant effects of sleep deprivation require astrocyte-dependent adenosine mediated signaling. Transl. Psychiatry 3, e212 (2013).

193. Szopa, A. et al. Agomelatine and tianeptine antidepressant activity in mice behavioral despair tests is enhanced by DMPX, a selective adenosine A2A receptor antagonist, but not $D P C P X$, a selective adenosine $A 1$ receptor antagonist. Pharmacol. Rep. 71, 676-681 (2019).

194. Iwata, M. et al. Psychological stress activates the inflammasome via release of adenosine triphosphate and stimulation of the purinergic type $2 \mathrm{X7}$ receptor. Biol. Psychiatry 80, 12-22 (2016).

195. Basso, A. M. et al. Behavioral profile of $P 2 X 7$ receptor knockout mice in animal models of depression and anxiety: relevance for neuropsychiatric disorders. Behav. Brain Res. 198, 83-90 (2009).

196. Oliveira, S. et al. Impact of genetic variations in ADORA2A gene on depression and symptoms: a cross-sectional population-based study. Purinergic Signal. 15, 37-44 (2019).

197. Deussing, J. M. \& Arzt, E. P2X7 Receptor: A Potential Therapeutic Target For Depression? Trends Mol. Med. 24, 736-747 (2018).

198. Bartoli, F., Burnstock, G., Crocamo, C. \& Carra, G. Purinergic signaling and related biomarkers in depression. Brain Sci. 10, 160 (2020).

199. Bleehen, T. \& Keele, C. A. Observations on the algogenic actions of adenosine compounds on the human blister base preparation. Pain 3, 367-377 (1977).

200. Cook, S. P., Vulchanova, L., Hargreaves, K. M., Elde, R. \& McCleskey, E. W. Distinct ATP receptors on pain-sensing and stretch-sensing neurons. Nature $\mathbf{3 8 7}$, 505-508 (1997).

201. Sokolova, E., Nistri, A. \& Giniatullin, R. The ATP-mediated fast current of rat dorsal root ganglion neurons is a novel effector for $G A B A(B)$ receptor activation. Neurosci. Lett. 338, 181-184 (2003).

202. He, Y. Q. et al. P2X3 receptor-mediated visceral hyperalgesia and neuronal sensitization following exposure to PTSD-like stress in the dorsal root ganglia of rats. Neurogastroenterol. Motil. 29, e12976 (2017).

203. Goldman, N. et al. Adenosine A1 receptors mediate local anti-nociceptive effects of acupuncture. Nat. Neurosci. 13, 883-888 (2010)

204. Tang, Y., Yin, H. Y., Rubini, P. \& Illes, P. Acupuncture-induced analgesia: a neurobiological basis in purinergic signaling. Neuroscientist 22, 563-578 (2016)

205. He, J. R., Yu, S. G., Tang, Y. \& Illes, P. Purinergic signaling as a basis of acupuncture-induced analgesia. Purinergic Signal. 16, 297-304 (2020).

206. Vulchanova, L. et al. Cytotoxic targeting of isolectin IB4-binding sensory neurons. Neuroscience 108, 143-155 (2001).

207. Zhou, Y. F. et al. Suppressing PKC-dependent membrane P2X3 receptor upregulation in dorsal root ganglia mediated electroacupuncture analgesia in rat painful diabetic neuropathy. Purinergic Signal. 14, 359-369 (2018).

208. Tang, Y., Yin, H. Y., Liu, J., Rubini, P. \& Illes, P. P2X receptors and acupuncture analgesia. Brain Res. Bull. 151, 144-152 (2019).

209. da Silva Ferreira, N. C., Alves, L. A. \& Soares-Bezerra, R. J. Potential therapeutic applications of $\mathrm{P} 2$ receptor antagonists: from bench to clinical trials. Curr. Drug Targets 20, 919-937 (2019)

210. Chen, $Z$. et al. Controlling murine and rat chronic pain through $A 3$ adenosine receptor activation. FASEB J. 26, 1855-1865 (2012).

211. Seymour, R. A., Hawkesford, J. E., Hill, C. M., Frame, J. \& Andrews, C. The efficacy of a novel adenosine agonist (WAG 994) in postoperative dental pain. Br. J. Clin. Pharmacol. 47, 675-680 (1999).
212. Jarvis, M. F. et al. A-317491, a novel potent and selective non-nucleotide antagonist of $\mathrm{P} 2 \mathrm{X} 3$ and $\mathrm{P} 2 \mathrm{X} 2 / 3$ receptors, reduces chronic inflammatory and neuropathic pain in the rat. Proc. Natl Acad. Sci. USA 99, 17179-17184 (2002).

213. McGaraughty, S. et al. Effects of A-317491, a novel and selective P2X3/P2X2/3 receptor antagonist, on neuropathic, inflammatory and chemogenic nociception following intrathecal and intraplantar administration. Br. J. Pharmacol. 140, 1381-1388 (2003).

214. Eser, A. et al. Safety and efficacy of an oral inhibitor of the purinergic receptor P2X7 in adult patients with moderately to severely active Crohn's disease: a Randomized Placebo-controlled, Double-blind, Phase Ila Study. Inflamm. Bowel Dis. 21, 2247-2253 (2015).

215. Burnstock, G. Purinergic mechanisms and pain. Adv. Pharm. 75, 91-137 (2016).

216. Ji, R. R., Chamessian, A. \& Zhang, Y. Q. Pain regulation by non-neuronal cells and inflammation. Science 354, 572-577 (2016).

217. Hartlova, A. et al. DNA damage primes the type I interferon system via the cytosolic DNA sensor STING to promote anti-microbial innate immunity. Immunity 42, 332-343 (2015)

218. Wang, X. \& Chen, D. Purinergic regulation of neutrophil function. Front. Immunol. 9, 399 (2018).

219. Deaglio, S. et al. Adenosine generation catalyzed by CD39 and CD73 expressed on regulatory $\mathrm{T}$ cells mediates immune suppression. J. Exp. Med. 204, 1257-1265 (2007).

220. Linden, J., Koch-Nolte, F. \& Dahl, G. Purine release, metabolism, and signaling in the inflammatory response. Annu. Rev. Immunol. 37, 325-347 (2019).

221. Raczkowski, F. et al. CD39 is upregulated during activation of mouse and human $T$ cells and attenuates the immune response to Listeria monocytogenes. PLoS ONE 13, e0197151 (2018).

222. Dosch, M., Gerber, J., Jebbawi, F. \& Beldi, G. Mechanisms of ATP Release by Inflammatory Cells. Int. J. Mol. Sci. 19, 1222 (2018).

223. Wang, J. \& Dahl, G. Pannexin1: a multifunction and multiconductance and/or permeability membrane channel. Am. J. Physiol. Cell Physiol. 315, C290-C299 (2018).

224. Sridharan, M. et al. Pannexin 1 is the conduit for low oxygen tension-induced ATP release from human erythrocytes. Am. J. Physiol. Heart Circ. Physiol. 299, H1146-H1152 (2010).

225. Savio, L. E. B., de Andrade Mello, P., da Silva, C. G. \& Coutinho-Silva, R. The P2X7 receptor in inflammatory diseases: angel or demon? Front. Pharmacol. 9, 52 (2018).

226. Di Virgilio, F., Dal Ben, D., Sarti, A. C., Giuliani, A. L. \& Falzoni, S. The P2X7 receptor in infection and inflammation. Immunity 47, 15-31 (2017).

227. Gourine, A. V. et al. P2 receptor blockade attenuates fever and cytokine responses induced by lipopolysaccharide in rats. Br. J. Pharmacol. 146, 139-145 (2005).

228. Vergani, A. et al. Long-term heart transplant survival by targeting the ionotropic purinergic receptor P2X7. Circulation 127, 463-475 (2013).

229. Fowler, B. J. et al. Nucleoside reverse transcriptase inhibitors possess intrinsic anti-inflammatory activity. Science 346, 1000-1003 (2014).

230. Franceschini, $A$. et al. The $P 2 X 7$ receptor directly interacts with the NLRP3 inflammasome scaffold protein. FASEB J. 29, 2450-2461 (2015).

231. Tschopp, J. \& Schroder, K. NLRP3 inflammasome activation: the convergence of multiple signalling pathways on ROS production? Nat. Rev. Immunol. 10, 210-215 (2010).

232. Solle, $M$. et al. Altered cytokine production in mice lacking $P 2 X(7)$ receptors. J. Biol. Chem. 276, 125-132 (2001).

233. He, Y., Franchi, L. \& Nunez, G. TLR agonists stimulate Nlrp3-dependent IL-1beta production independently of the purinergic $\mathrm{P} 2 \mathrm{X} 7$ receptor in dendritic cells and in vivo. J. Immunol. 190, 334-339 (2013).

234. Adinolfi, E. et al. Accelerated tumor progression in mice lacking the ATP receptor P2X7. Cancer Res. 75, 635-644 (2015).

235. Sakaki, $H$. et al. $P 2 X 4$ receptor regulates $P 2 X 7$ receptor-dependent IL-1beta and IL-18 release in mouse bone marrow-derived dendritic cells. Biochem. Biophys. Res. Commun. 432, 406-411 (2013).

236. Adriouch, $\mathrm{S}$. et al. $\mathrm{NAD}^{+}$released during inflammation participates in $\mathrm{T}$ cell homeostasis by inducing ART2-mediated death of naive T cells in vivo. J. Immunol. 179, 186-194 (2007).

237. Hubert, $\mathrm{S}$. et al. Extracellular $\mathrm{NAD}^{+}$shapes the Foxp3 ${ }^{+}$regulatory $\mathrm{T}$ cell compartment through the ART2-P2X7 pathway. J. Exp. Med. 207, 2561-2568 (2010).

238. Matzinger, P. Friendly and dangerous signals: is the tissue in control? Nat. Immunol. 8, 11-13 (2007).

239. Amores-Iniesta, J. et al. Extracellular ATP activates the NLRP3 inflammasome and is an early danger signal of skin allograft rejection. Cell Rep. 21, 3414-3426 (2017).

240. Adriouch, S., Haag, F., Boyer, O., Seman, M. \& Koch-Nolte, F. Extracellular NAD ${ }^{+}$: a danger signal hindering regulatory T cells. Microbes Infect. 14, 1284-1292 (2012) 
241. Scheuplein, F. et al. NAD ${ }^{+}$and ATP released from injured cells induce P2X7dependent shedding of $\mathrm{CD} 62 \mathrm{~L}$ and externalization of phosphatidylserine by murine T cells. J. Immunol. 182, 2898-2908 (2009).

242. Haag, F. et al. Extracellular NAD and ATP: Partners in immune cell modulation. Purinergic Signal. 3, 71-81 (2007).

243. Koch-Nolte, F., Fischer, S., Haag, F. \& Ziegler, M. Compartmentation of $\mathrm{NAD}^{+}$-dependent signalling. FEBS Lett. 585, 1651-1656 (2011).

244. Samuels, S. E., Lipitz, J. B., Dahl, G., Muller, K. J. \& Neuroglial, A. T. P. release through innexin channels controls microglial cell movement to a nerve injury. J. Gen. Physiol. 136, 425-442 (2010).

245. Moreschi, I. et al. Extracellular $\mathrm{NAD}^{+}$is an agonist of the human P2Y11 purinergic receptor in human granulocytes. J. Biol. Chem. 281, 31419-31429 (2006).

246. Gerner, R. R. et al. NAD metabolism fuels human and mouse intestinal inflammation. Gut 67, 1813-1823 (2018).

247. O'Donnell, J. S., Teng, M. W. L. \& Smyth, M. J. Cancer immunoediting and resistance to T cell-based immunotherapy. Nat. Rev. Clin. Oncol. 16, 151-167 (2019).

248. Yin, J. et al. Potential mechanisms connecting purine metabolism and cancer therapy. Front. Immunol. 9, 1697 (2018).

249. Bianchi, G. et al. ATP/P2X7 axis modulates myeloid-derived suppressor cell functions in neuroblastoma microenvironment. Cell Death Dis. 5, e1135 (2014).

250. Bellefeuille, S. D., Molle, C. M. \& Gendron, F. P. Reviewing the role of P2Y receptors in specific gastrointestinal cancers. Purinergic Signal. 15, 451-463 (2019).

251. White, N. \& Burnstock, G. P2 receptors and cancer. Trends Pharmacol. Sci. 27 211-217 (2006).

252. Overes, I. M. et al. Expression of P2X5 in lymphoid malignancies results in LRH-1specific cytotoxic T-cell-mediated lysis. Br. J. Haematol. 141, 799-807 (2008).

253. de Rijke, B. et al. A frameshift polymorphism in P2X5 elicits an allogeneic cytotoxic $T$ lymphocyte response associated with remission of chronic myeloid leukemia. J. Clin. Investig. 115, 3506-3516 (2005).

254. De Marchi, E. et al. The P2X7 receptor modulates immune cells infiltration, ectonucleotidases expression and extracellular ATP levels in the tumor microenvironment. Oncogene 38, 3636-3650 (2019).

255. Di Virgilio, F. Purines, purinergic receptors, and cancer. Cancer Res. 72 5441-5447 (2012)

256. Grygorczyk, R., Furuya, K. \& Sokabe, M. Imaging and characterization of stretchinduced ATP release from alveolar A549 cells. J. Physiol. 591, 1195-1215 (2013).

257. Martins, I. et al. Chemotherapy induces ATP release from tumor cells. Cell Cycle 8, 3723-3728 (2009)

258. Adinolfi, E. et al. Basal activation of the P2X7 ATP receptor elevates mitochondrial calcium and potential, increases cellular ATP levels, and promotes serumindependent growth. Mol. Biol. Cell 16, 3260-3272 (2005).

259. Adinolfi, E. et al. Trophic activity of a naturally occurring truncated isoform of the P2X7 receptor. FASEB J. 24, 3393-3404 (2010).

260. Adinolfi, E. et al. Expression of $P 2 X 7$ receptor increases in vivo tumor growth. Cancer Res. 72, 2957-2969 (2012).

261. Marteau, F. et al. Thrombospondin-1 and indoleamine 2,3-dioxygenase are major targets of extracellular ATP in human dendritic cells. Blood 106, 3860-3866 (2005)

262. Agteresch, H. J., Dagnelie, P. C., van der Gaast, A., Stijnen, T. \& Wilson, J. H. Randomized clinical trial of adenosine $5^{\prime}$-triphosphate in patients with advanced non-small-cell lung cancer. J. Natl Cancer Inst. 92, 321-328 (2000).

263. Agteresch, H. J. et al. Beneficial effects of adenosine triphosphate on nutritional status in advanced lung cancer patients: a randomized clinical trial. J. Clin. Oncol. 20, 371-378 (2002).

264. Zhou, Y. et al. The adenosine A1 receptor antagonist DPCPX inhibits tumo progression via the ERK/JNK pathway in renal cell carcinoma. Cell. Physiol. Biochem. 43, 733-742 (2017).

265. Kalhan, A. et al. Adenosine $A 2 A$ and $A 2 B$ receptor expression in neuroendocrine tumours: potential targets for therapy. Purinergic Signal. 8, 265-274 (2012).

266. Torres, A. et al. Extracellular adenosine promotes cell migration/invasion of glioblastoma stem-like cells through A3 adenosine receptor activation under hypoxia. Cancer Lett. 446, 112-122 (2019).

267. Ohta, A. et al. A2A adenosine receptor protects tumors from antitumor T cells. Proc. Natl Acad. Sci. USA 103, 13132-13137 (2006).

268. Sitkovsky, M. et al. Adenosine A2A receptor antagonists: blockade of adenosinergic effects and T regulatory cells. Br. J. Pharmacol. 153, S457-S464 (2008).

269. Stagg, J. et al. CD73-deficient mice have increased antitumor immunity and are resistant to experimental metastasis. Cancer Res. 71, 2892-2900 (2011).

270. Stagg, J. et al. CD73-deficient mice are resistant to carcinogenesis. Cancer Res. 72, 2190-2196 (2012)

271. Ledderose, $\mathrm{C}$. et al. Adenosine arrests breast cancer cell motility by $\mathrm{A} 3$ receptor stimulation. Purinergic Signal. 12, 673-685 (2016)

272. Fajardo, A. M., Piazza, G. A. \& Tinsley, H. N. The role of cyclic nucleotide signaling pathways in cancer: targets for prevention and treatment. Cancers 6, 436-458 (2014).
273. DeRubertis, F. R. \& Craven, P. A. Sequential alterations in the hepatic content and metabolism of cyclic AMP and cyclic GMP induced by DL-ethionine: evidence for malignant transformation of liver with a sustained increase in cyclic AMP. Metabolism 25, 1611-1625 (1976).

274. Aleksijevic, A. et al. Alterations of peripheral blood lymphocyte cyclic AMP and cyclic GMP in untreated patients with hodgkin's disease. Clin. Immunol. Immunopathol. 26, 398-405 (1983).

275. Heinonen, P. K. \& Metsa-Ketela, T. Prostanoids and cyclic nucleotides in malignant and benign ovarian tumors. Med. Oncol. Tumor Pharmacother. 5, 11-15 (1988).

276. Pearce, L. R., Komander, D. \& Alessi, D. R. The nuts and bolts of AGC protein kinases. Nat. Rev. Mol. Cell Biol. 11, 9-22 (2010)

277. Naviglio, S. et al. Protein kinase A as a biological target in cancer therapy. Expert Opin. Ther. Targets 13, 83-92 (2009).

278. Kania, E., Roest, G., Vervliet, T., Parys, J. B. \& Bultynck, G. IP3 receptor-mediated calcium signaling and its role in autophagy in cancer. Front. Oncol. 7, 140 (2017).

279. Khalafalla, F. G. et al. P2Y2 nucleotide receptor prompts human cardiac progenitor cell activation by modulating Hippo signaling. Circ. Res. 121, 1224-1236 (2017).

280. Grol, M. W., Brooks, P. J., Pereverzev, A. \& Dixon, S. J. P2X7 nucleotide receptor signaling potentiates the Wnt/beta-catenin pathway in cells of the osteoblast lineage. Purinergic Signal. 12, 509-520 (2016).

281. Masse, K. \& Dale, N. Purines as potential morphogens during embryonic development. Purinergic Signal. 8, 503-521 (2012).

282. Sorrentino, C. et al. Adenosine A2A receptor stimulation inhibits TCR-induced Notch1 activation in CD8 ${ }^{+}$T-cells. Front. Immunol. 10, 162 (2019).

283. Gonzalez, E. J., Heppner, T. J., Nelson, M. T. \& Vizzard, M. A. Purinergic signalling underlies transforming growth factor-beta-mediated bladder afferent nerve hyperexcitability. J. Physiol. 594, 3575-3588 (2016).

284. Ghiringhelli, F. et al. Activation of the NLRP3 inflammasome in dendritic cells induces IL-1 beta-dependent adaptive immunity against tumors. Nat. Med. 15, 1170-1178 (2009).

285. Torralba, K. D., De Jesus, E. \& Rachabattula, S. The interplay between diet, urate transporters and the risk for gout and hyperuricemia: current and future directions. Int. J. Rheum. Dis. 15, 499-506 (2012).

286. Choi, H. K., Atkinson, K., Karlson, E. W., Willett, W. \& Curhan, G. Purine-rich foods, dairy and protein intake, and the risk of gout in men. N. Engl. J. Med. 350, 1093-1103 (2004).

287. Zgaga, L. et al. The association of dietary intake of purine-rich vegetables, sugarsweetened beverages and dairy with plasma urate, in a cross-sectional study. PLOS ONE 7, e38123 (2012).

288. Choi, H. K., Liu, S. \& Curhan, G. Intake of purine-rich foods, protein, and dairy products and relationship to serum levels of uric acid: the Third National Health and Nutrition Examination Survey. Arthritis Rheum. 52, 283-289 (2005).

289. Burnstock, G. Purinergic signaling in the cardiovascular system. Circ. Res. 120 207-228 (2017).

290. Tsushima, Y. et al. Uric acid secretion from adipose tissue and its increase in obesity. J. Biol. Chem. 288, 27138-27149 (2013).

291. Villegas, R. et al. Purine-rich foods, protein intake, and the prevalence of hyperuricemia: the Shanghai Men's Health Study. Nutr. Metab. Cardiovasc. Dis. 22, 409-416 (2012).

292. Chuang, S. Y., Lee, S. C., Hsieh, Y. T. \& Pan, W. H. Trends in hyperuricemia and gout prevalence: nutrition and Health Survey in Taiwan from 1993-1996 to 2005-2008. Asia. Pac. J. Clin. Nutr. 20, 301-308 (2011).

293. Garrel, D. R. et al. Milk- and soy-protein ingestion: acute effect on serum uric acid concentration. Am. J. Clin. Nutr. 53, 665-669 (1991).

294. Dalbeth, N. et al. Acute effect of milk on serum urate concentrations: a randomised controlled crossover trial. Ann. Rheum. Dis. 69, 1677-1682 (2010).

295. Choi, H. K., Willett, W. \& Curhan, G. Coffee consumption and risk of incident gout in men: a prospective study. Arthritis Rheum. 56, 2049-2055 (2007).

296. Kela, U., Vijayvargiya, R. \& Trivedi, C. P. Inhibitory effects of methylxanthines on the activity of xanthine oxidase. Life Sci. 27, 2109-2119 (1980).

297. Li, X. N. et al. Screening the active compounds of Phellodendri Amurensis cortex for treating prostate cancer by high-throughput chinmedomics. Sci. Rep. 7, 46234 (2017).

298. Ma, X. et al. The pathogenesis of diabetes mellitus by oxidative stress and inflammation: its inhibition by berberine. Front. Pharmacol. 9, 782 (2018).

299. Li, L. et al. The defensive effect of phellodendrine against AAPH-induced oxidative stress through regulating the AKT/NF-kappaB pathway in zebrafish embryos. Life Sci. 157, 97-106 (2016).

300. Guo, S. et al. Magnoflorine ameliorates lipopolysaccharide-induced acute lung injury via suppressing NF-kappaB and MAPK activation. Front. Pharmacol. 9, 982 (2018).

301. Chi, X., Zhang, H., Zhang, S. \& Ma, K. Chinese herbal medicine for gout: a review of the clinical evidence and pharmacological mechanisms. Chin. Med. 15, 17 (2020). 
302. Zhang, W. et al. Constituents and anti-hyperuricemia mechanism of traditional Chinese herbal formulae erding granule. Molecules 24, 3248 (2019).

303. Fukuoka, S. \& Arita, R. Increase in tear film lipid layer thickness after instillation of $3 \%$ diquafosol ophthalmic solution in healthy human eyes. Ocul. Surf. 15, 730-735 (2017).

304. Ohashi, Y. et al. Long-term safety and effectiveness of diquafosol for the treatment of dry eye in a real-world setting: a Prospective Observational Study. Adv. Ther. 37, 707-717 (2020).

305. Abdulqawi, R. et al. P2X3 receptor antagonist (AF-219) in refractory chronic cough: a randomised, double-blind, placebo-controlled phase 2 study. Lancet 385, 1198-1205 (2015).

306. Smith, J. A. et al. Gefapixant, a P2X3 receptor antagonist, for the treatment of refractory or unexplained chronic cough: a randomised, double-blind, controlled, parallel-group, phase 2b trial. Lancet. Respir. Med 8, 775-785 (2020).

307. Kanthi, Y., Knight, J. S., Zuo, Y. \& Pinsky, D. J. New (re)purpose for an old drug: purinergic modulation may extinguish the COVID-19 thromboinflammatory firestorm. JCl Insight 5, e140971 (2020).

308. Cardoso, A. M. COVID-19 and purinergic signaling: the need for investigation. Purinergic Signal. 16, 451-452 (2020).

309. Di Virgilio, F., Tang, Y., Sarti, A. C. \& Rossato, M. A rationale for targeting the P2X7 receptor in Coronavirus disease 19. Br. J. Pharmacol. 177, 4990-4994 (2020).
310. Abbracchio, M. P., Jacobson, K. A., Müller, C. E. \& Zimmermann, H. W. Professor Dr. Geoffrey Burnstock (1929-2020). Purinergic Signal. 16, 137-149 (2020).

311. Verkhratsky A., Zimmermann, H. W., Abbracchio, M. P., Illes P. \& Di Virgilio, F. In Memoriam Geoffrey Burnstock: creator of purinergic signaling. Function 1, e6 (2020).

(C) Open Access This article is licensed under a Creative Commons Attribution 4.0 International License, which permits use, sharing, adaptation, distribution and reproduction in any medium or format, as long as you give appropriate credit to the original author(s) and the source, provide a link to the Creative Commons license, and indicate if changes were made. The images or other third party material in this article are included in the article's Creative Commons license, unless indicated otherwise in a credit line to the material. If material is not included in the article's Creative Commons license and your intended use is not permitted by statutory regulation or exceeds the permitted use, you will need to obtain permission directly from the copyright holder. To view a copy of this license, visit http://creativecommons. org/licenses/by/4.0/.

(c) The Author(s) 2021 